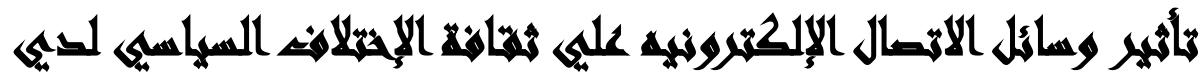 الهوايبر
}

$[\wedge]$

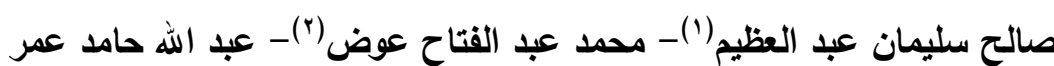

( ) كلية الآداب، جامعة عين شمس.ب) كلية الآداب، جامعة الزقازيق.

\section{المستخله}

أمام التدفق المعلوماتى غير المدقق وغير المكلف لجأت كثير من وسائل الإعلام المكتوبة

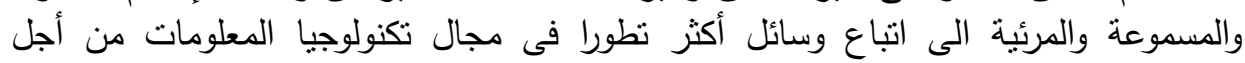

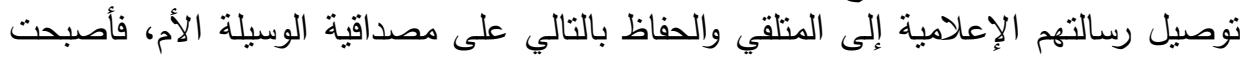

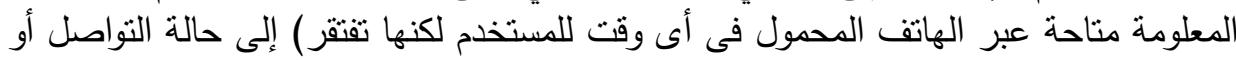

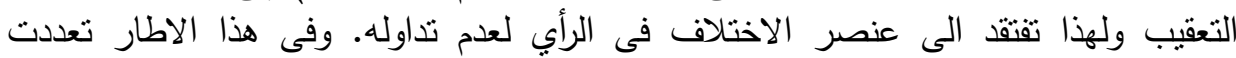

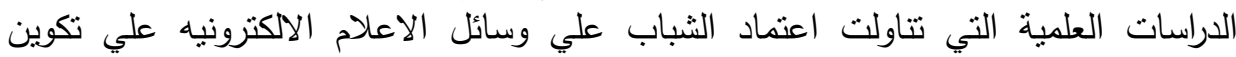

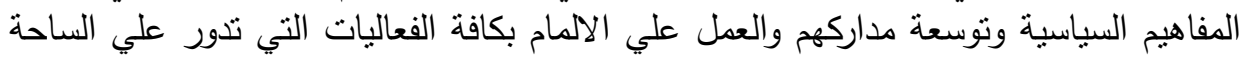

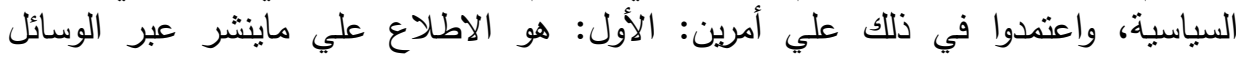

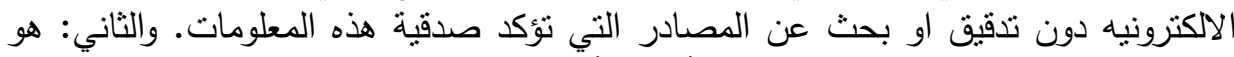

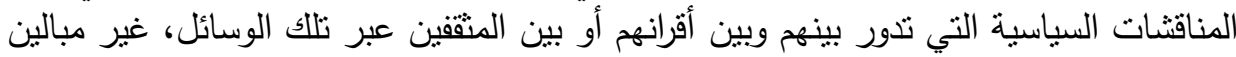

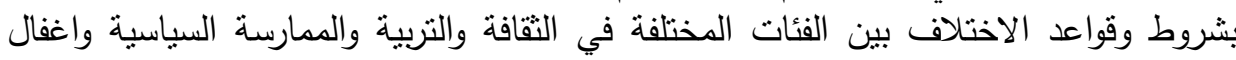

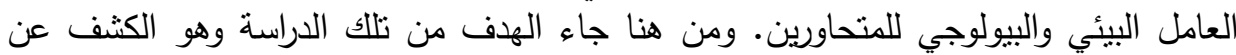

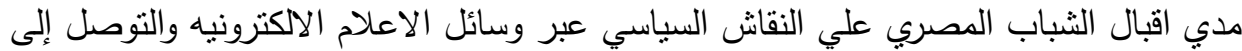
سلوكيات الثباب المصري حال الاختلاف السياسي عبر وسائل الإعلام الإلكترونية. وتكتسب الإنس الإنس

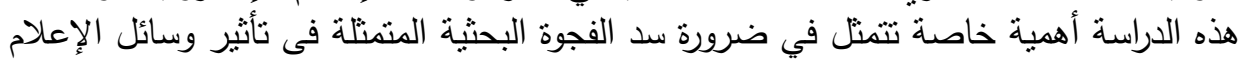

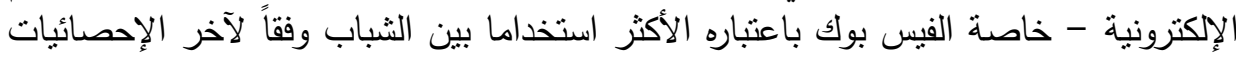

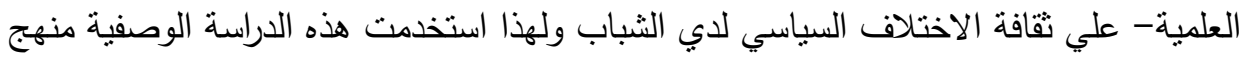

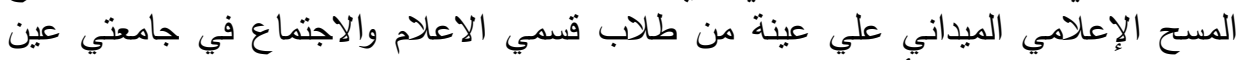

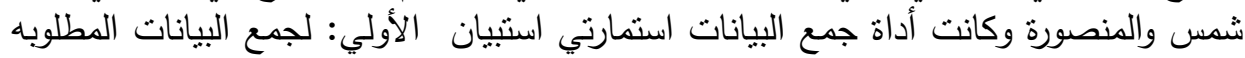

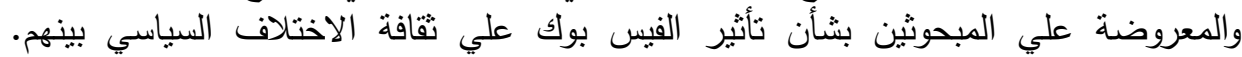

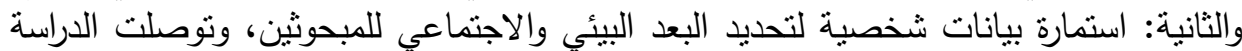

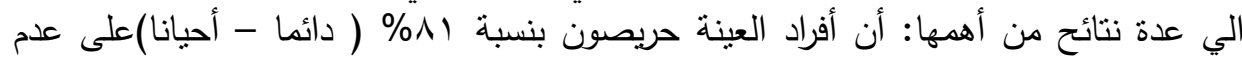

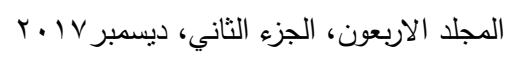


حدوث خلاف سياسى وذلك لما له من أضرار على الانقسام بين الزملاء أو الخصام والتطاول.

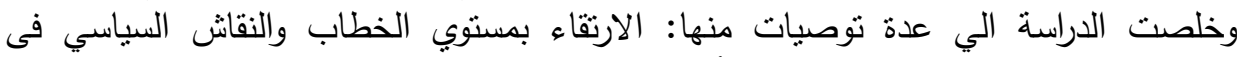

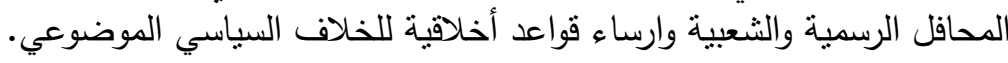

\section{ramidl}

أثشارت دراسات علمية متعددة الي اعتماد الثباب اعتمادا مباشرا وكاملا على وسائل

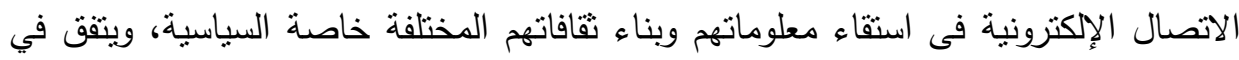
هذا كثير من الباحثين أمثال أحمد سمير في دراسته استخدام الثباب الجامعي المصري للمواقع

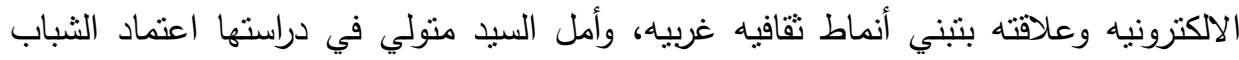
المصري علي شبكة التواصل الاجتماعي في أوقات الازمات خلال المرحلة الانتقاليه ــ وغيرهم . واستطاع النشطاء السياسيون توظيفها في الحراك السياسي الذي شهدته بعض من الدواهل الدول العربيه

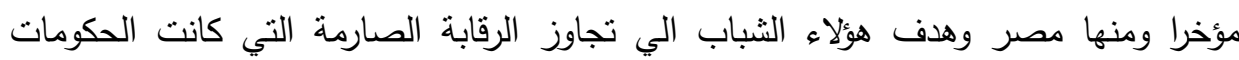

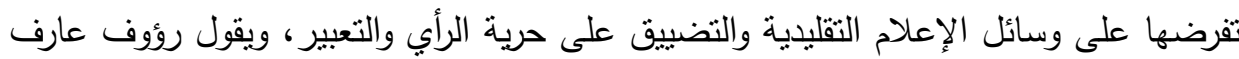
في دراسته الثبكات الاجتماعيه والنشاط السياسي في الدول السلطويه دراسة مقارنه للتغيير

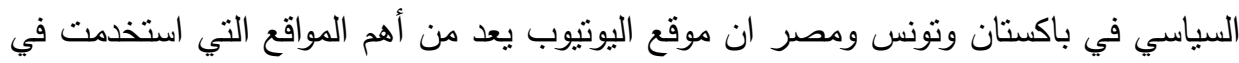

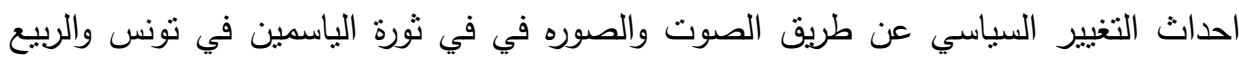

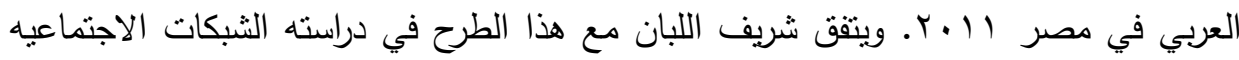

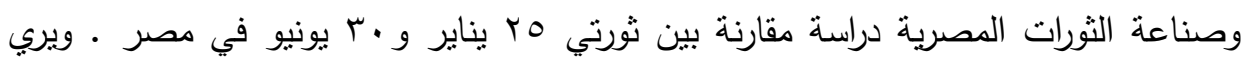

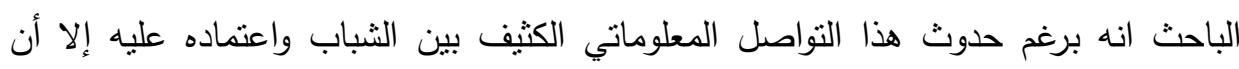

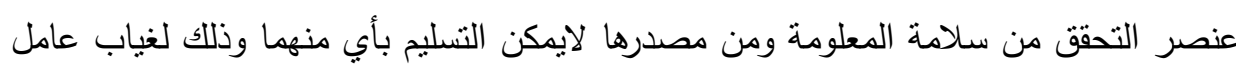
التواصل الاجتماعي وعدم دقة المعلومات الثخصية من صاحب أى من الرسالتين المرسلة

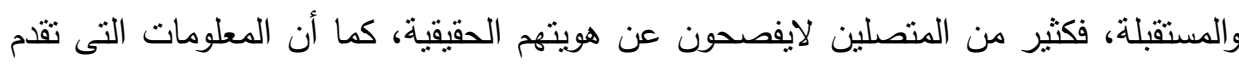

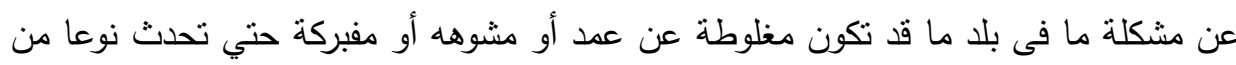

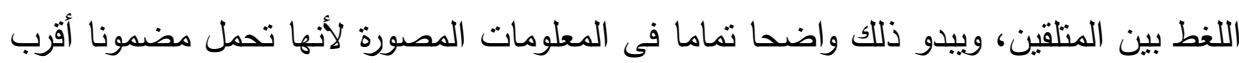


إلى التصديق منها إلى الثكك بسبب العوامل التقنية المستخدمة من صوت وصورة وديكور وإضاءة وغيرها، الأمر الذي يحدث اختلافا بين عنصري التواصل يصل في أحبان كثيره إلى ضياع الحقيقة، وهذا مادأبت علي اتباعه بعض القنوات الفضائيه العربيه في تغطياتها لثورة

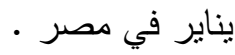

\section{xarax}

قام الباحث باجراء دراسة اسنطلاعية علي عينة عشوائية من شباب الجامعة اختار لها عشرة مفردات من طلاب جامعة عين شمس باعنبارها جامعة حضرية وعشرة مفردات من طلاب جامعة المنصورة باعتبارها جامعة إقليمية للاطلاع علي اهتمام الثباب بالثأن السياسي والقيام

بالنقاش السياسي عبر وسائل الاتصال الالكترونيه، وتوصلت الاراسة الي النتائج التالية: - توفر الاهنمام لدي الثباب في كلتا الجامعتين بالثنأن السياسي العام. - اعتماد الثباب علي الفيس بوك كوسيلة اتصال الكترونيه الحصول علي المعلومات السياسية بلية فيلية بدلا من المواقع الرسمية لوسائل الاعلام الأخرى من صحافة وإذاعة وتليفزيون والمواقع

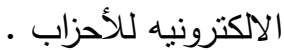

- حدوث خلاف واضح بين الثباب لابي مناقشتهم القضايا السياسية مع بعضهم البعض أو مع

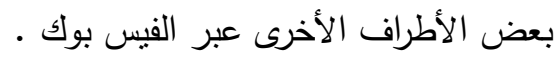

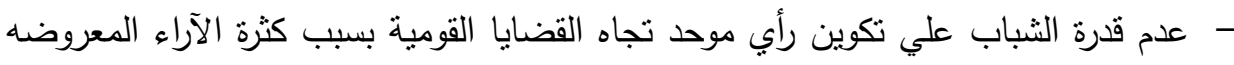

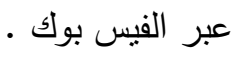

- عدم قدرة الثباب علي توظيف الخلاف في وجهات النظر السياسية المطروحة علي الفيس

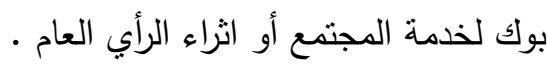

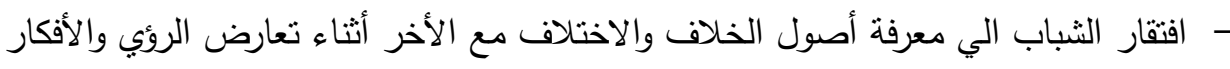


وبعد الاطلاع علي الدراسات التي أجريت بشأن العلاقة بين الثباب ووسائل الاتصال

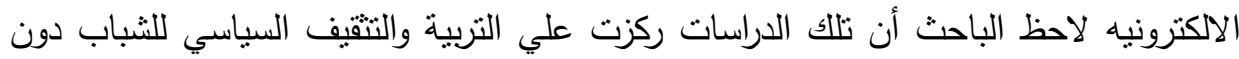
الاخذ في الاعتبار تدريب هؤلاء الثباب علي كيفية استثمار الخلاف السياسي بين الطوائف

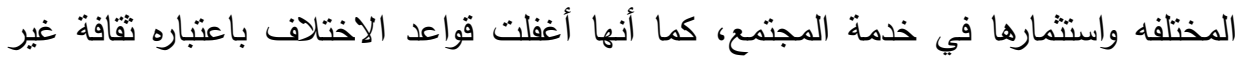
معيبه، الأمر الذي اعتبره الباحث فجوة بحثيه عمل علي سدها من خلال تلك الدراسة.

\section{تمساولاهي التوراسة}

تتحدد تساؤلاات الدراسـة في التساؤل الرئيسي التالي: ما تأثير وسائل الاتصال الإككترونية علي ثقافة الاختلاف السياسي لدي الثباب؟ وينبثق عن هذا التساؤل بعض الأسئلة الفرعية الآتية:

ا ـ ما مدى وجود اهنمات سياسية لاى الثباب ؟ r. ما معدل استخدام الثباب لوسائل الاتصال الإكترونية ؟

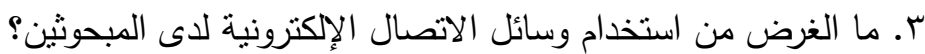

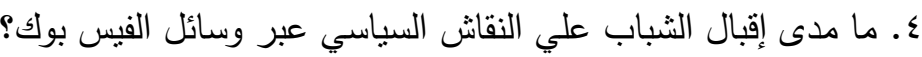

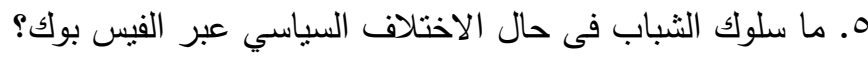

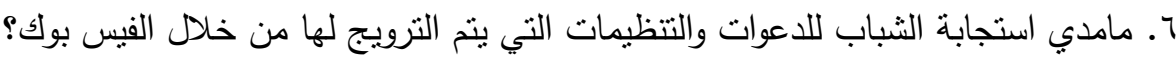

\section{أهمية السراسة}

تبرز قيمة الدراسة من خلا الأهمية التي باتت ضرورية للجهات الرسمية في الدوله التي تهنت بمشاركة الثباب السياسية والمجتمعيه، ومن تلك الجهات مجلس النواب والجهات السيادية في البلاد فضلا عن وزارة التربية والتعليم ووزراة الثباب والرياضة ووسائل الاعلام المختلفه ونه ولهن تقليدية كانت ام الكترونيه، إضافة الي الأحزاب السياسية ومنظمات المجتمع المدني. وتنرز أهمية الدراسة أيضا في سد الفجوة البحثية المتمنلة فى ثأثثير وسائل الإعلام الإلكترونية - 
خاصة الفيس بوك باعتباره الأكثر استخداما بين الثباب وفقاً لآخر الإحصائيات العلمية- علي تقافة الاختلاف السياسي لدي الثباب.

\section{أهسا اهن التواسـ}

تهزف هذه الدراسة إلي:

1. التعرف على مدى وجود اهتماتمات سياسية لدى الثباب. r. التوصل إلى معدل استخدام الثباب لوسائل الاتصال الإكترونية.

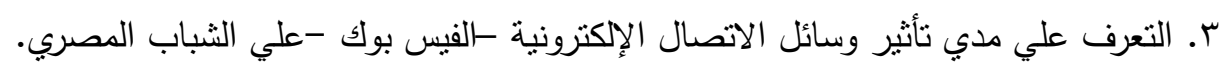
ع. الكثف عن مدي اقبال الثباب المصري علي النقاش السياسي عبر وسائل الاعلام الالكترونيه.

ه. التوصل إلى سلوكيات الثباب المصري حال الاختلاف السياسي عبر وسائل الإعلام الإلكترونية. 7. التعرف علي مدي استجابة الثباب للاعوات السياسية عبر وسائل الإعلام الإلكترونية.

\section{هزوضر السراسمة}

ا. الفرض الأول: توجد فروق ذات دلالة إحصائية بين المبحوثين وفق متغير البيئة الجغرافية

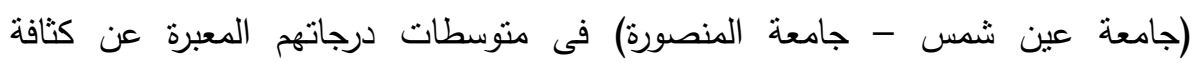
استخدامهم لوسائل الاتصال الإكترونية.

r. الفرض الثانى: توجد فروق ذات دلالة إحصائية بين المبحوثين وفق متغير البيئة الجغرافية

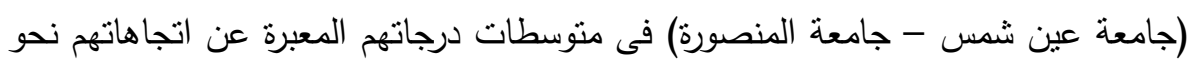
الخلاف السياسى.

r. الفرض الثالث: توجد فروق ذات دلالة إحصائية بين المبحوثين وفق متغير (المستوى

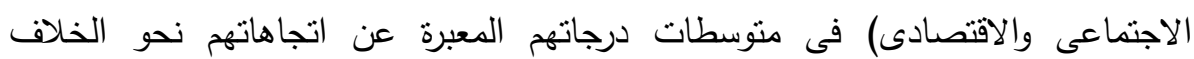

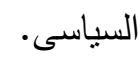


ء. الفرض الرابع: توجد علاقة إيجابية ذات دلالة إحصائية بين كثافة استخدام المبحوثين

$$
\text { لوسائل الاتصال الإلكترونية وبين اتجاهاتهم نحو الخلاف السياسى. }
$$

ه. الفرض الخامس: نوجد علاقة إيجابية ذات دلالة إحصائية بين مدى قيام المبحوثين بمناقثنة الإنية القضايا السياسية عبر وسائل الاتصال الإككترونية، وبين اتجاهاتهم نحو الخلاف السياسى.

\section{التراسايت المايري}

أولاً: دراسات تتعلق بوسائل الاتصال الالكترونية وعلاقتها ببعض المتغيرات

1) مجدي الداغر (10) (10): موضوع الدراسة: "ثنبكات التواصل الاجتماعي بمصر : بديل

$$
\text { إعلامي يواجه الاستقطاب". }
$$

أهمية الدراسة: دراسة السلوك الاتصالي لفئة الثباب المصري وعلاقتته بشبكات النواصل

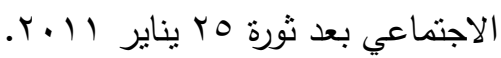

أهداف الدراسة: تحديد طبيعة السلوك الاتصالي للشباب المصري، والدور المتعاظم لثبكات

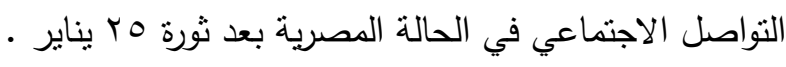

أهم نتائج الدراسة: الثباب المصري يستخدم شبكات التواصل الاجتماعي باعتبارها إعلامًا بديلًا

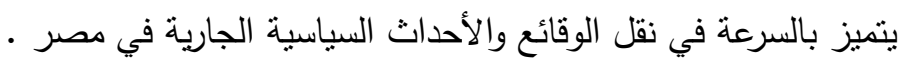

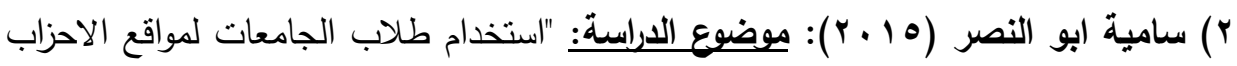

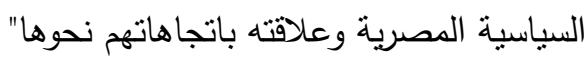

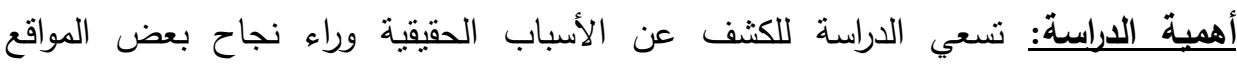
الالكترونية الخاصة بالأحزاب السياسية فى الوصول للجمهور المستهدف ونوعيته بأهية 
أهم نتائج الداسية: عدم تأثير المواقع الآكترونية للاحزاب السياسية فى تغيير اتجاهات الثباب تجاه عدد من القضايا التي تطرحها الاحزاب لعدم نقة الشباب في تلك الأحزاب او عدم اهتمامهم بيرامجها.

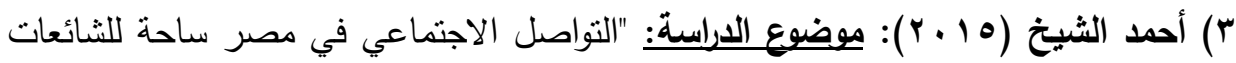
والتحريض. مرسي والبرادعي وشفيق فثلوا في استخدام "فيسبوك وتوتير".

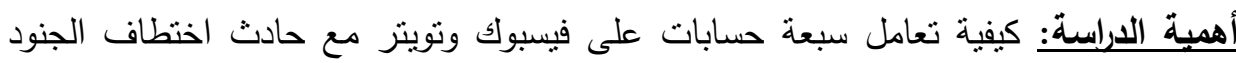

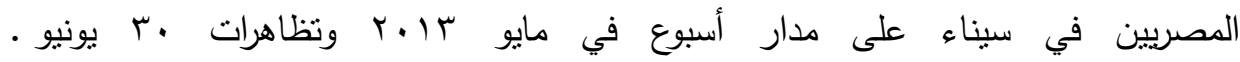
أهداف الاراسية: معرفة النواقص التي يمكن ان تحدث أثناء استخدام وسائل الاتصال الاكترونيه ومدي تأثير ذلك علي مستوبي القادة السياسيين. أهم نتائج الدراسة: أثنارت الدراسة إلى أن محمد مرسي الرئيس المصري الاسبق فثل في

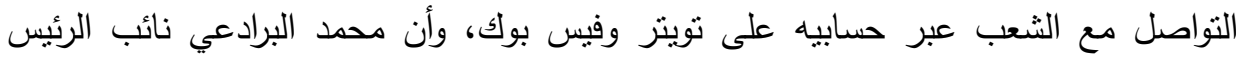

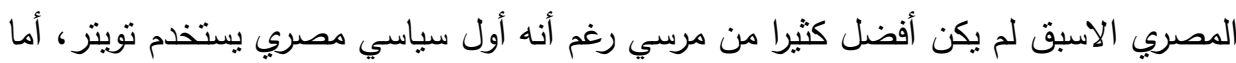
أحمد شفيق المرشح الرئاسي السابق فقد استخدم تويتر بشكل مفرط خلال فترة اختطاف الجنود

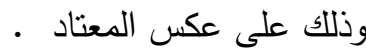

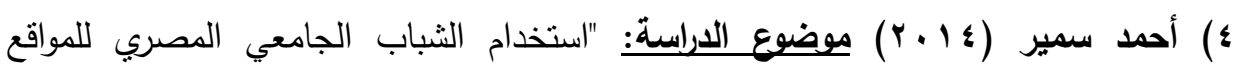
الاككترونية وعلاقته بتبني أنماظ ثقافية غربية. أهمبة الدراسة: الحد من انتثار الانماط الغربية الثقافية بين الثباب الجامعي المصري لما له له من نأثثر مباشر علي الانماط الثقافية العربية. أهداف الاراسة: دراسة تفشي وانتشار الانماط الثقافية الغربية بين الثباب الجامعي المصري وعلاقته باستخدام وسائل الاعلام الالكترونيه

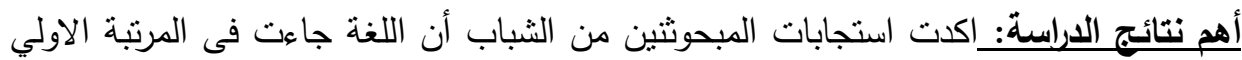
ثم طريقة التفكير ثم العادات والتقاليد فى ترتيب الانماط الثقافية التي تؤثر فى مستخدمي مواقع

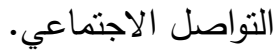




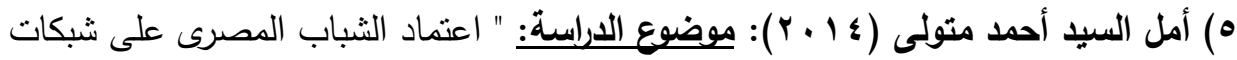

التواصل الاجتماعى فى أوقات الأزمات خلال المرحلة الانتقالية"

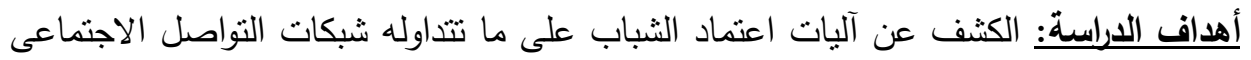
فى أوقات الأزمات خلال المرحلة الإنتقالية مع تحديد العوامل المؤثرة فى ذلك. أهم نتائج الاراسة:جاء موقع اليوتيوب فى الترتيب الثانى من حيث كونه أكثر المواقع تفضيلاً

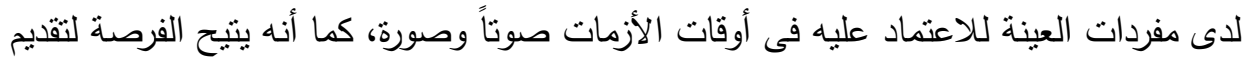

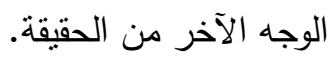

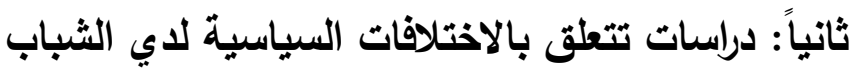

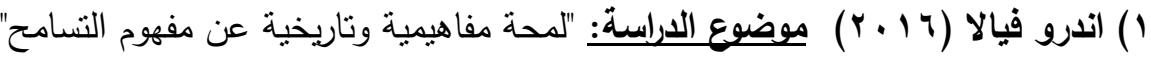
أهمبة الدراسة: تري الدراسة ان النسامح الأخلاقي برتبط بفكرة سياسية حول ضبط سلطة الدولة،

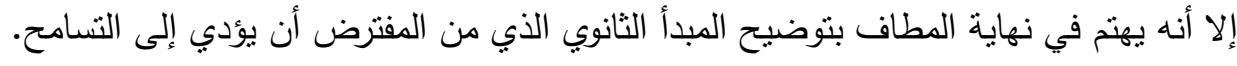
أهم نتائج الدراسة: نأصيل عملية التسامح السياسي فى ثناث نقاط: احترام الخصوصية، والفصل ما بين الكنيسة (المرجعية الدينيه) والدولة، واحترام حقوق الإنسان.

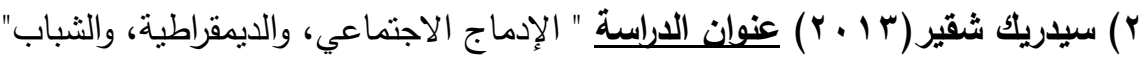

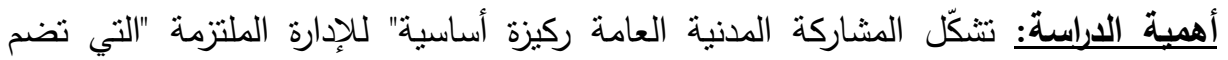

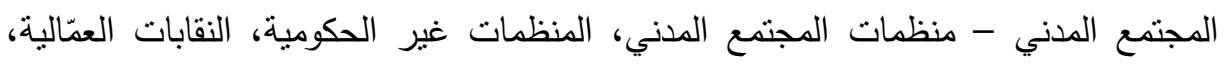
الطوائف الدينية إلى حقل التخطيط السياسي. أهداف الدراسة: قياس مدي ارتباط كل من المشاركة المدنية وتتمية الثباب بعملية المشاركة الديمقراطية وصنع القرار والمساهمة في المجتمع.

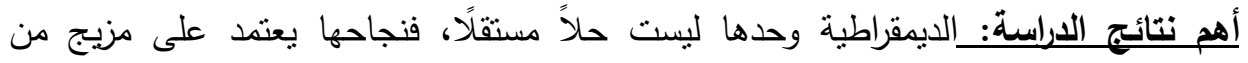
متغيرات منوقّعة وغير متوقّعة وتقوم العلاقة بين المشاركة والديمقراطية على التعزيز المنبادل : المشاركة هي محرّك هام للايمقراطية وتؤثّر هذه الأخيرة في المشاركة والعمليات التشاركية. 


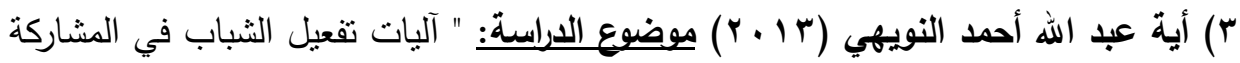

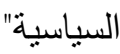

أهمبة الدراسة: بحث دور الإعلام بشقيه الالكتروني والتقليدي فى تدعيم ثقافة المشاركة

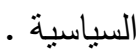

أهداف الدراسة: توضيح الربط الذي حدث بين ثورة الاتصالات والمعلومات وبين التطور • السياسي والديمقراطي أهم نتائج (لاراسة: - تؤدى وسائل الإعلام دورًا رئيسيًا وفاعلا في نتكيل سياق التحول السياسي في المجتمعات

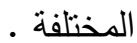
- لوسائل الإعلام قدرة مهمة في تتكيل المدركات السياسية للأفراد من خلال تزويدهم بالمعلومات عن الثؤون والقضايا السياسية.

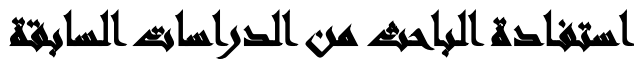

باستعراض الدراسات السابقة يتضح انها تختلف احيانا فيما بينها فى الموضوع والهدف والمنهج والأدوات المستخدمه وتتفق احيانا أخري، ولهذا فقد أفادت الباحث في دراسته كالأتي: - تكوين رؤية واضحة نحو المشكلة البحثية من حيث تحديدها وصياغتها. - صياغة تساؤلات الدراسة بشكل علمي يحقق اهداف الدراسة. - تصميم استمارة الاستبيان المتعلقة بالدراسة. - - تحديد المفاهيم والمصطلحات المستخدمة فى الدراسة.

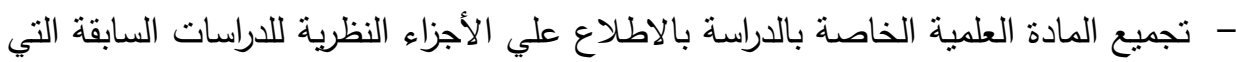
تقيد موضوع الدراسة. - تحديد مجتمع البحث وعينة الدراسة. 
- تفسيرالنتائج حيث استعان الباحث ببعض نتائج الدراسات السابقة قريبة الصلة بدراسة الباحث لاجراء المقارنات للوقوف علي أوجه الاتفاق والاختلاف بين نتاج هذه الدراسة والدراسات السابقه. - اختيار أنسب المناهج والأدوات الخاصة بجمع المعلومات والبيانات بالاضافة الي المقاييس الاحصائية المناسبة لنوع الدراسة. - معرفة أهم المراجع العربية والأجنبية التي يمكن الاستعانة بها واختيار الاطار النظري لـاني المناسب للاسراسة.

\section{الاطار اللنظريه للتصواسة}

اختار الباحث نظرية الاعتماد على وسائل الإعلام والتى سيوضحها فى التالى: تعد نظرية الاعتماد على وسائل الإعلام إحدى النظريات التي اهتمت برصد ودراسة تأثيرات

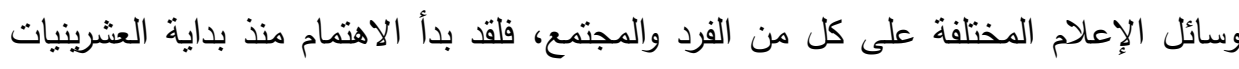

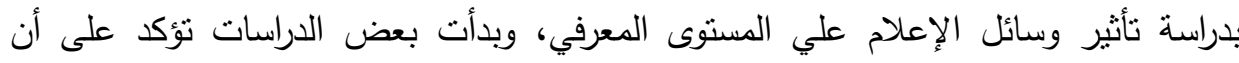
اختلاف مستوى المعرفة لدى الأفراد لا يرجع إلى اختلاف في سمات الجمهور وخصائصسه

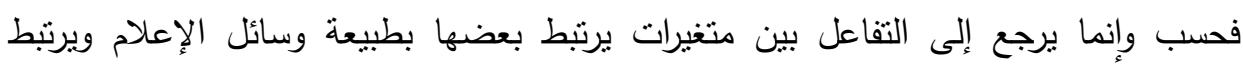

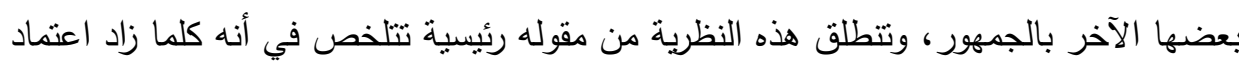

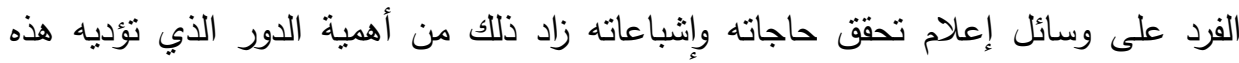

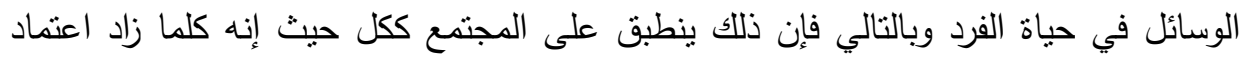

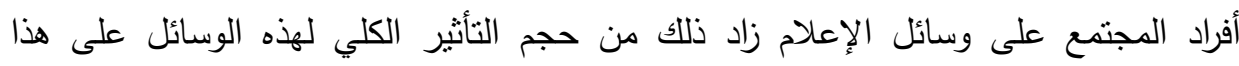

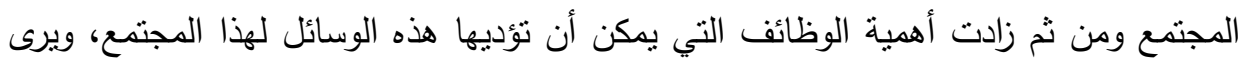

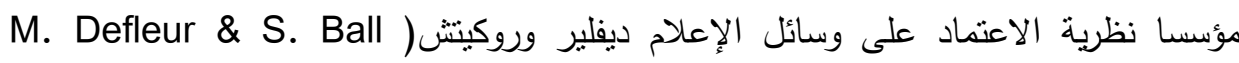
Rokeach

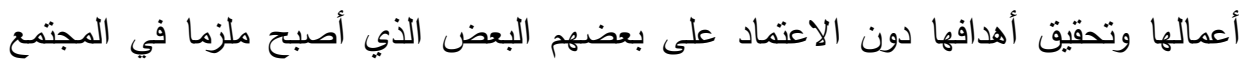


الحديث. وتعتمد فكرة هذه النظرية على أن استخدامنا لوسائل الإعلام لا يتم بمعزل عن تأثثر

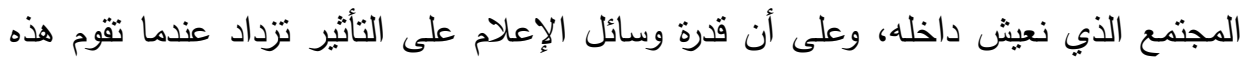

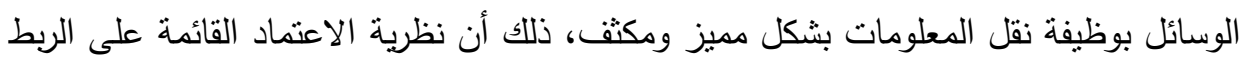

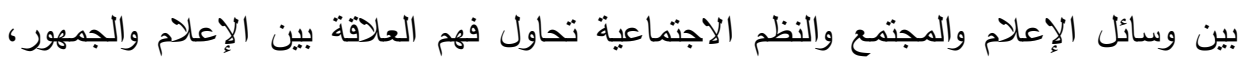
وتركز في هذا على إجابة سؤال (لماذا يتابع الجمهور وسائل الإعلام لتحقيق الهدف؟).

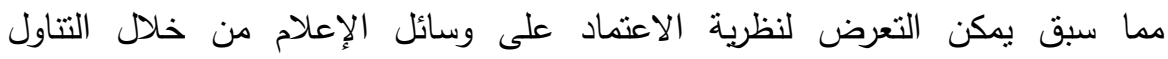

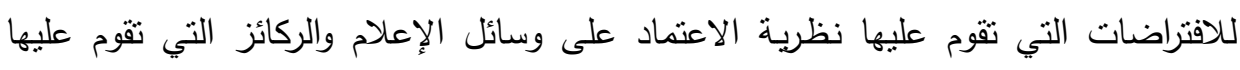
علاقات الاعتماد على وسائل الإعلام، والنموذج المتكامل لنظرية الاعتماد على وسائل الإعلام والآثار الناتجة عن اعتماد الأفراد على وسائل الإعلام، وكذللك أسباب ارتفاع نسبة الاعتماد

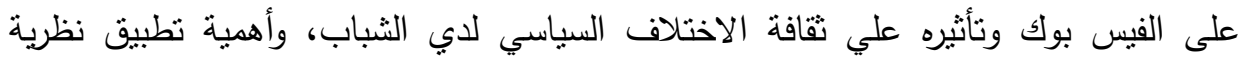

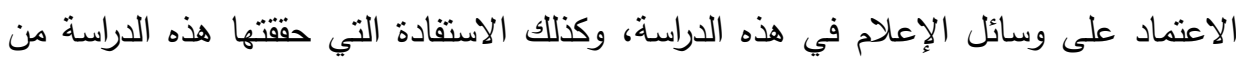

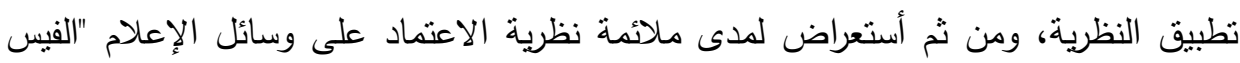
بوك" لربطه بهذه الدراسة.

(1) الافتراضات التي تقوم عليها نظرية الاعتماد على وسائل الإعلام: نقوم نظرية الاعتماد

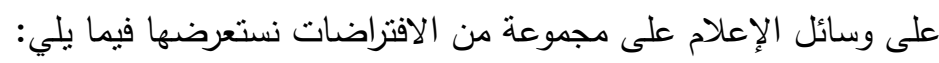

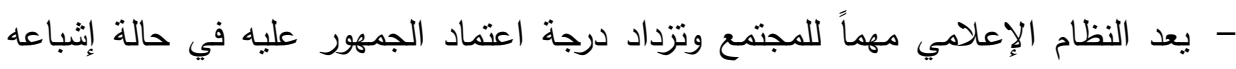

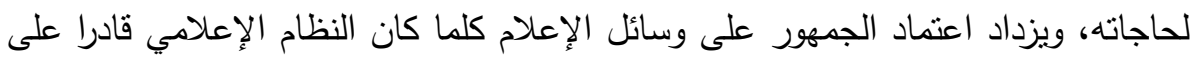

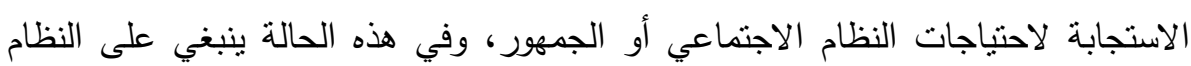
الإعلامي أن يتطور - الإنيه

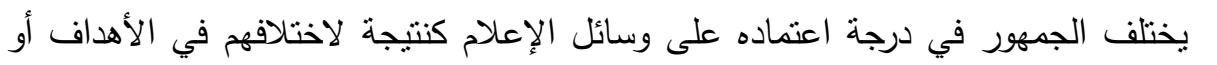
المصالح والحاجات الفردية، ويختلف الجمهور من حيث اعتماده على وسائل الإعلام (الصفوة قمة الهرم) قد يكون له وسائل إعلامه الخاصة به غير الوسائل التقليدية

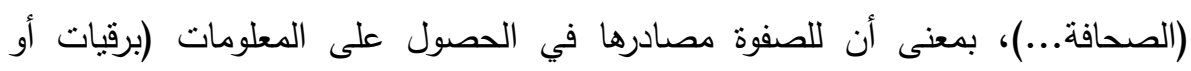

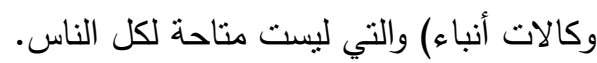


• تختلف درجة استقرار النظام الاجتماعي وتوازنه نتيجة التغيرات المستمرة وتبعاً لهذا الاختلاف تزيد أو نقل الحاجة إلى المعلومات والأخبار ففي حالة عدم الاستقرار الاجتماعي تلفيه

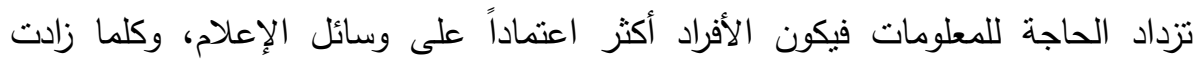
التغيرات والأزمات في المجتمع زادت حاجة المجتمع للمعلومات (أي تغيير اجتماعي أو الون

$$
\text { سباسي أو اقتصادي). }
$$

(Y) الركائز التي تقوم عليها علاقات الاعتماد على وسائل الإعلام:

وتقوم علاقات الاعتماد على وسائل الإعلام على ركيزتين أساسيتين هما:

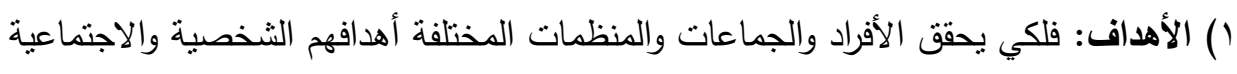
فإن عليهم أن يعتمدوا على موارد يسيطر عليها أنخاص أو جماعات أو منظمات أخرى

$$
\text { والعكس صحيح. }
$$

r) المصادر : يسعى الأفراد المراهقون الي المنظمات المختلفة التي تحقق أهدافهم، وتعد وسائل

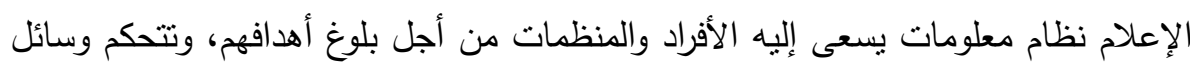

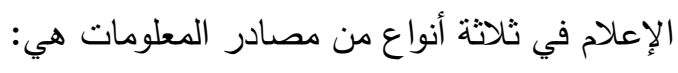

أ) المصدر الأول: جمع المعلومات: يقوم المندوب الصحفي بجمع المعلومات التي نحتاج إلى دنى

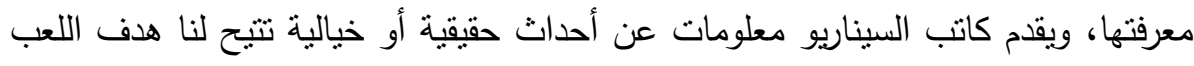

$$
\text { أو المرح أو الاسترخاء. }
$$

ب) المصدر الثاني: تتسيق المطومات: يشير تتسيق المعلومات إلى تتقيح المعلومات التي تم جمعها بالزيادة أو النقصان لكي تخرج بصورة مناسبة في شكل قصة صحفية أو برنامج

$$
\text { إذاعي أو فيلم سينمائي. }
$$

ج) المصدر الثالث: ذلك أن اعتماد الجمهور على مصادر المعلومات يمكن أن يميز من خلال ثلاث نقاط : مناط

- التوزيع: يختلف اعتماد الجمهور على مصادر المعلومات وهذا أساس اختلاف مستويات الاعتماد فيما بينهم، فالمراهقون يختلفون في مستوى الاعتماد على مصادر المعلومات. 
- المفاضلة: فمصادرها متتوعة والاختلاف يظهر في ممارسة انتقائية المعلومات فهناك من

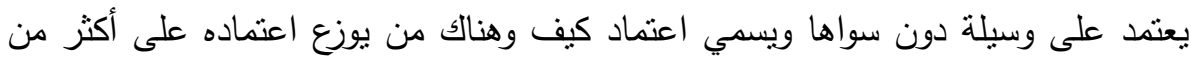

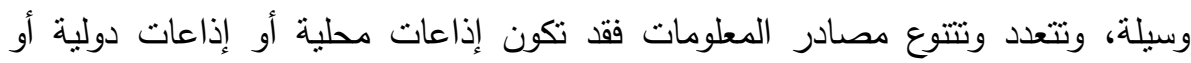
قنوات تليفزيونية أرضية أو فضائية أو الصحف، وهناك من المراهقين من يكثة اعتمادهاه على وسيلة واحدة ومنهم من يوزع اعتماده على أكثر من وسيلة.

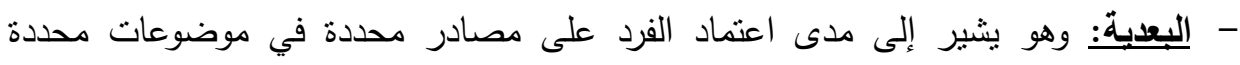

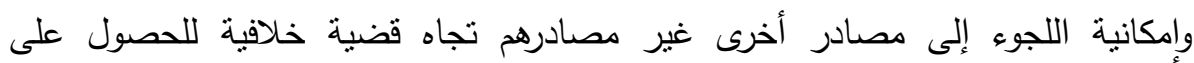
المعلومات.

وهناك مجالات عديدة يعتمد فيها الجمهور ومنهم الثباب على نظام وسائل الإعلام لتلبية أهدافهم المعرفية في إطار الحاجة إلى معرفة العالم الاجتماعي حولنا، معرفة تمثل المعاني

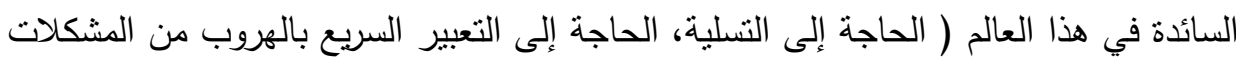
اليومية والقضاء على التوتر التي تسببه)، وهذه كلها حاجات يلبيها نظام وسائل الإعلام

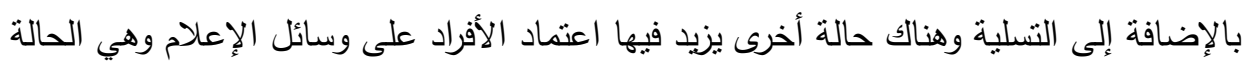

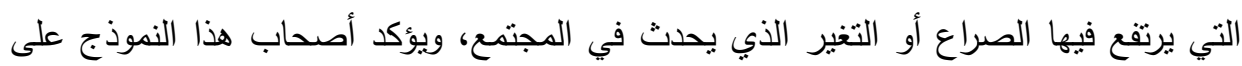

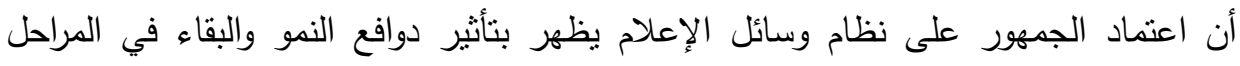

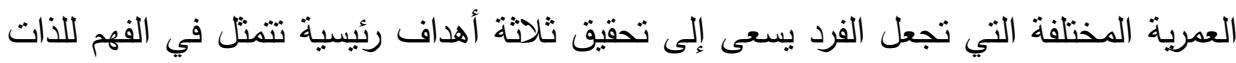
والعالم المحيط به ثم توجيه الفرد إلى الأنماط السلوكية والقرارات الخاصة والاجتماعية وكذلك لكيه

فمن أجل الحصول على المعلومات وتوفيرها تتفاعل وسائل الإعلام مع النظم القائمة في المجتمع كالنظام السياسي والاقتصادي والتعليمي والديني والعسكري والقانوني، وتقوم العلاقة بين

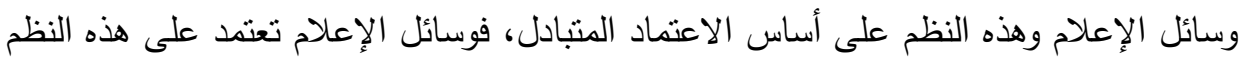

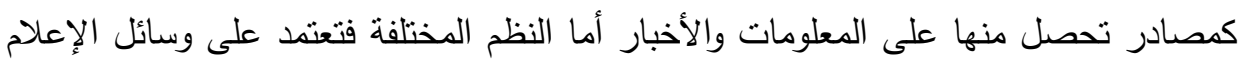
لتحقيق مصالحها واهتماماتها والوصول إلى الجماهير التي تعتمد بدورها على وسائل الإعلام للحصول على المعلومات الخاصة بهذه النظم القائمة في المجنمع. 
وتكمن قوة وسائل الإعلام طبقاً لنظرية الاعتماد هذه في سيطرة وسائل الإعلام على نظم

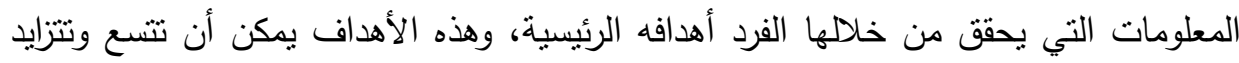

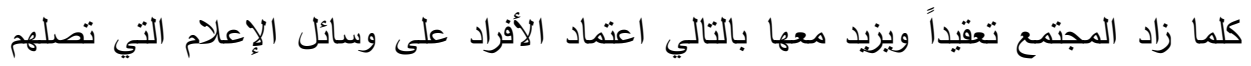
بمصادر المعلومات التي تحقق لهم هذه الأهداف.

(r) الآثار الناتجة عن اعتماد الأفراد على وسائل الإعلام: يثير صاحبا النظرية (ملفين دي فلور ، وساندرا بول روكيش) إلى الآثار المحتملة نتيجة اعتماد الفرد على وسائل الإنل

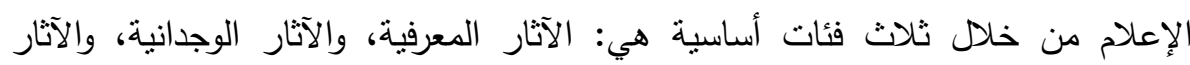

أولا) الآثار المعرفية Cognitve Effects : ويقصد بها زيادة الوعي والمعرفة، فوسائل

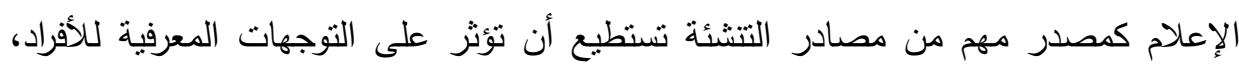

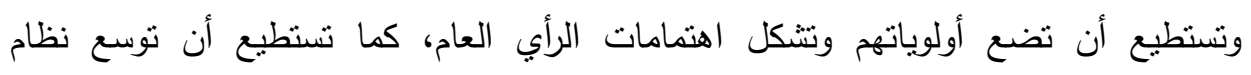
المعتقدات لدى الأفراد، مثل توسيع معتقدات الجمهور تجاه قضايا الفساد... إلخ، ونتنتمل الآثار

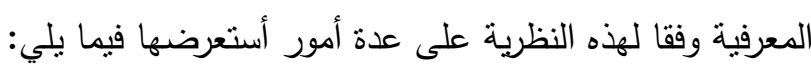

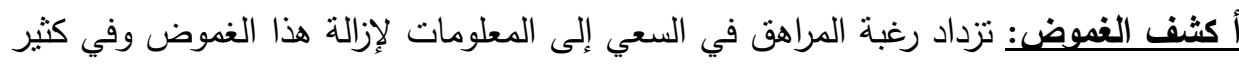

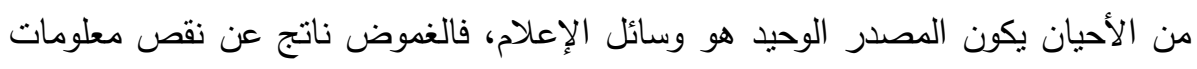

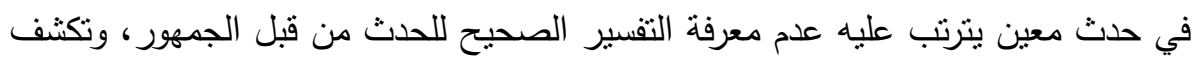
وسائل الإعلام الغموض من خلال تقديم التقسير الواضح للحدث أو زيادة المعلومات في هذه الحادثة. ب تكوين الاتجاه : تكون وسائل الإعلام الاتجاه لدى الجمهور مع عدم إغفال الدور الانتقائي للفرد في تكوين الاتجاه لديه كما في منل مشكلات البيئة والتربية. ج ترتيب الأولويات : ولهذا الأثر نظرية مستقلة تحمل الاسم نفسه، حيث إن وسائل الإنل الإعلام

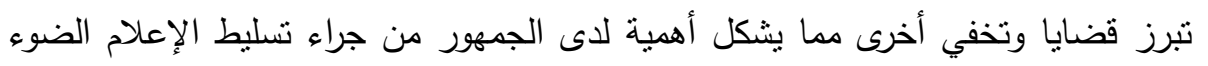
على قضية دون أخرى. 
دـ زيادة نظم المعتقدات: بجانب التأثير على نظم معتقدات المراهقين سواء كان بزيادة الفئات التي يمكن تتظيم هذه المعتقدات في إطارها أو زيادة المعنقدات في كل فئة وذلك مما يؤدي إلى اتساع نظام المعتقدات بالنسبة للمراهقين، فوسائل الإعلام تعلم الجمهور أنثياء ومعارف لا يدركونها من قبل مما يشكل لهم أهمية، وذلك منل الحرية في التعبير وأمر المساواة. ثانيا) الآثار الوجدانية Emotional Effects : يذكر (ملفين دي فلور وساندرا بول روكيش) صاحبا النظرية أن المقصود بالآثار الوجدانية هو المشاعر منل: العاطفة، والخوف، والدعم المعنوي ونعرضها على النحو الآتي:

أل الفتور العاطقي: فكثرة التعرض لوسائل الإعلام يؤدي بالفرد إلى الثعور بالفتور العاطفي

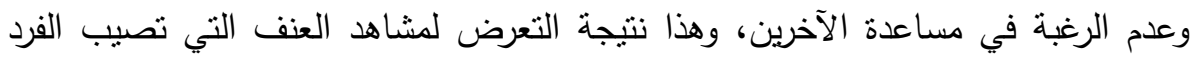

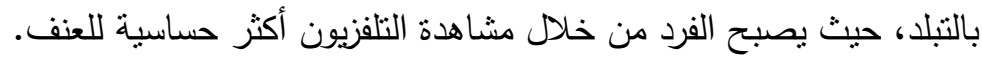
ب الخوف والقلق : يعد الخوف والقلق من الآثار الوجدانية لاعتماد المراهقين على وسائل

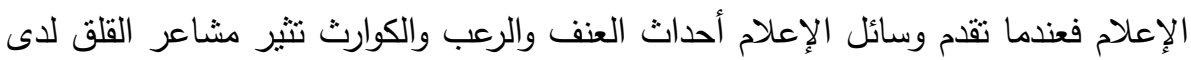

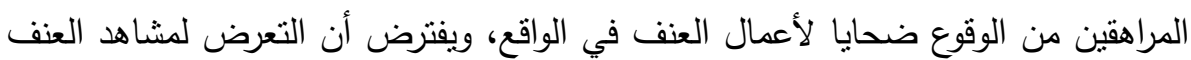
يصيب الفرد المتلقي بالخوف والقلق والرعب من الوقوع في هذه الأعمال أو أن يكون ضحية الاعمال

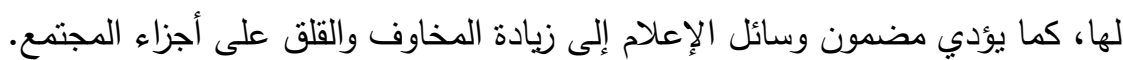

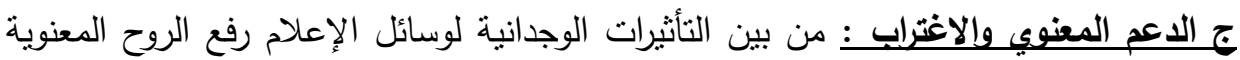

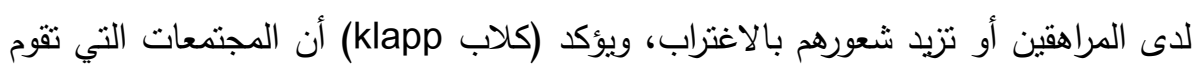

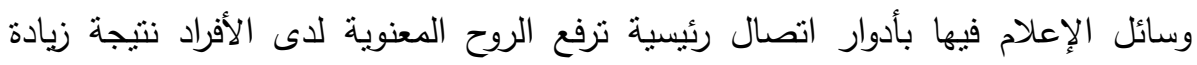
الثعور الجمعي والتوحيد والاندماج وخاصة إذا كانت وسائل الإعلام تعكس الفئات

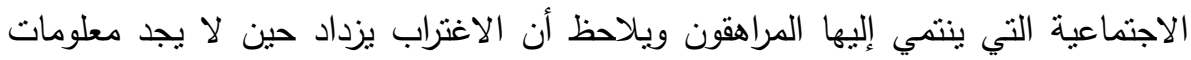

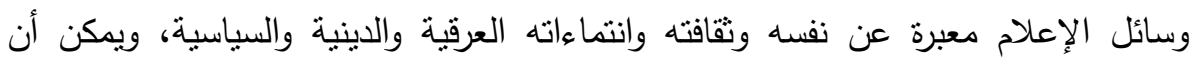
تحدث وسائل الإعلام بعض التغيرات في المعنويات ومنها الاغتراب من المجتمع. 
ثالثا) الآثار السلوكية Behavioral Effects: يحصر (دي فلور وساندرا بول روكيش) الآثار السلوكية المترتبة على اعتماد الفرد على وسائل الإعلام في أمرين: أ ـ التنشبط: ويعني به قيام الفرد بنشاط ما نتيجة التعرض لوسائل الإعلام، وهذا هو المئه المنتج

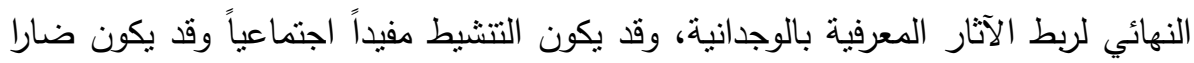

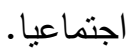

ب الخمول:الخمول يعني عدم النشاط وتجنب القيام بالفعل، وقد يحدث الخمول نتيجة تعرض المراهقين لتغطية إعلامية مبالغ فيها وينعكس في سلوكيات مثل العزوف عن المشاركة السياسية أو عدم الإدلاء بالتصويت الانتخابي وعدم المشاركة في أنشطة المجتمع، ويعني هذا العزوف عن العمل ولم يحظ هذا الجانب بالدراسة الكافية، ويحدث العزوف نتيجة التغطية المبالغ فيها مما يسب الملل.

ويفترض (ديفلير، وروكيتش) أن هناك مصدرين أساسيين للتغيير في طبيعة علاقات

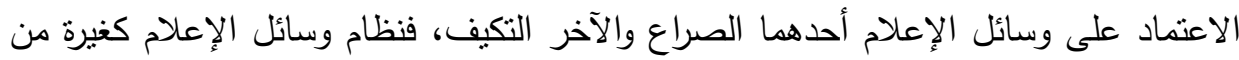
الأنظمة يبحث عن فرصة لزيادة السيطرة على مصادره إلى أقصى حد وتقليل تبعيتها إلى أدنى

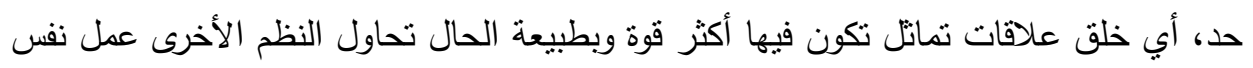

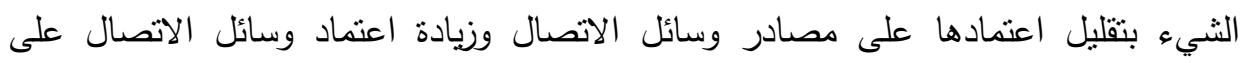

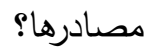
هذا بالنسبة للصراع أما بالنسبة للتكيف فإن النظم الاجتماعية لا تبقى كما هي بل تتطور دائما إلى أنثكال أكثر نعقيداً، وعلى ذلك فإن علاقات بلات الاعتماد المتبادل بين وسائل الإعلام

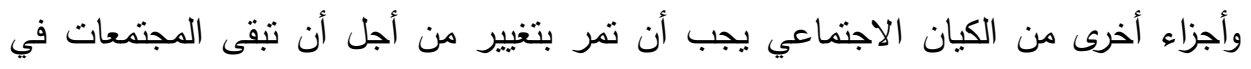

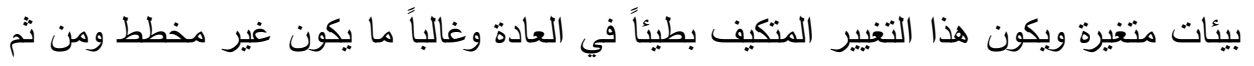
فإنه من الصعب إدراكه في الوقت الذي يقع فيه. (\&) أسباب ارتفاع نسبة الاعتماد على الفيس بوك : هناك العديد من أسباب نسبة الاعتماد على الفيس بوك على غيره من مواقع التواصل الاجتماعي ووسائل الإعلام في لإني 
الحصول على المعلومات عن القضايا والأحداث الجارية والنقاش والخلاف حولها وأستعرض الأن لأهم هذه الأسباب من خلال التعرض لنتائج الدراسة الاستطلاعية ونتائج الدراسات السابقة فيما يلي: - من خلال استعراض نتائج الدراسات السابقة يتضح أن هناك العديد من الأسباب التي أدت

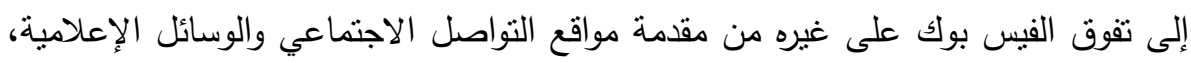

$$
\text { ومن هذه الأسباب ما يلي: }
$$

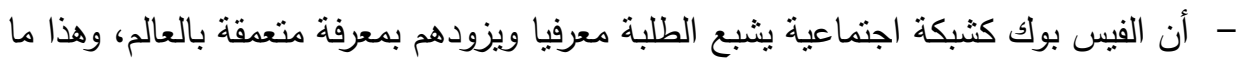
توصلت له نتائج دراسة صالحة الدماري( • ( • rم).

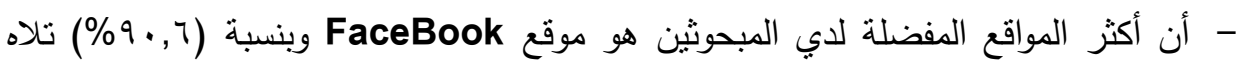

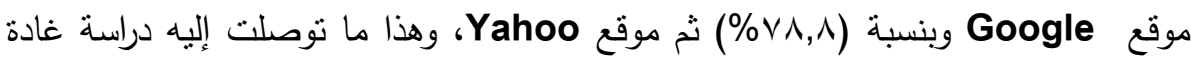

$$
\text { مصطفى أحمد محمد البطريق( (1) + rم). }
$$

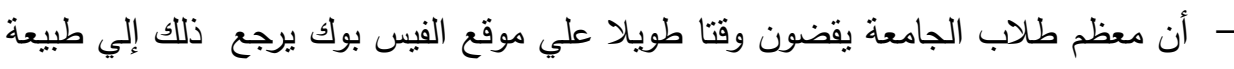

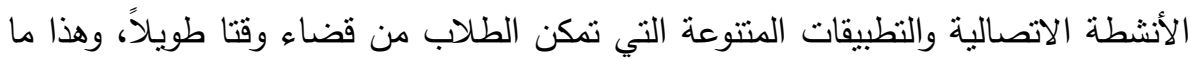

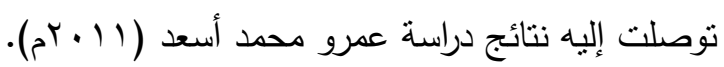

- أن من أهداف استخدام الفيس بوك هو مساعدة المستخدمين لمعرفة المزيد عن الأحداث

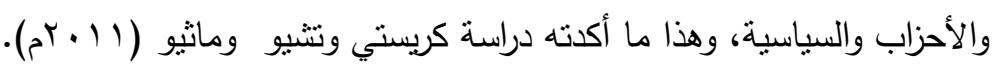
- أن الانترنت وشبكات التواصل الاجتماعي والفيس بوك على وجه التحديد هي الوسائل الأهم في التعرف على الحركات الاحتجاجية، وذللك للثقة في مصداقية الصفحات وللقائمين عليها

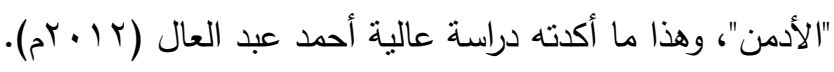

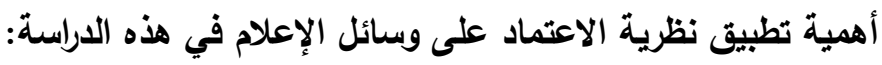
ترجع أهية اعتماد هذه الدراسة على نظرية الاعتماد على وسائل الإعلام إلى ستة اعنى اعنبارات - تعتمد فكرة هذه النظرية على أن استخدامنا لوسائل الإعلام لا يتم بمعزل عن تأثير المجتمع

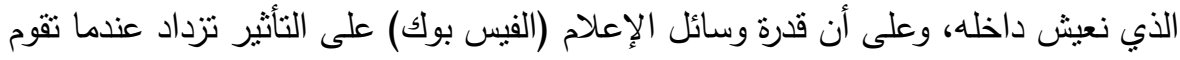

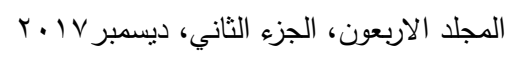


هذه الوسائل بوظيفة نقل المعلومات (حول القضايا السياسية في مصر) بشكل مميز ومكثف، وهذا هو الهذف الرئيسي للاراسة والمتمثل في (التعرف على تأثير وسائل الاتصال

$$
\text { الإلكترونية-الفيس بوك- علي ثقافة الاختلاف السياسي لاي الثباب). }
$$

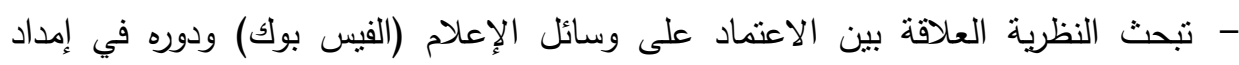
الجمهور بالمعلومات (وفي هذه الدراسة يتم التركيز على الفيس بوك ومدى نأثيره على ثقافة

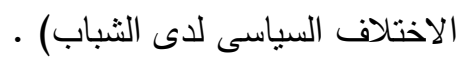

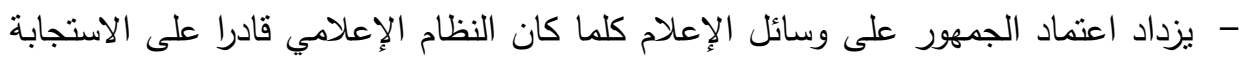

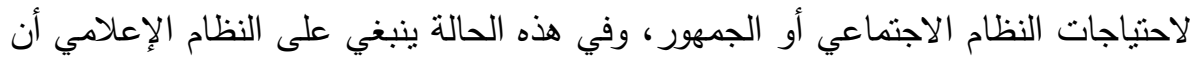
يتطور، وتسعى هذه الدراسة للوقوف على (الفروق بين الثباب الجامعي عينة الدراسة في مستوى اختلافهم السياسى باختلاف درجة كثافة التعرض للفيس بوك).

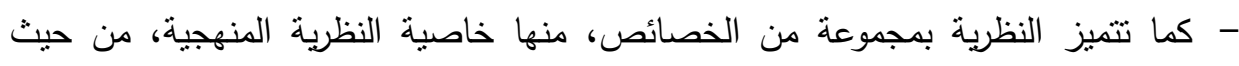
احتوائها على خطوات منهجية ثابته ومنظمة، واستخدامها أدوات بحثية، يمكنها من الحصول

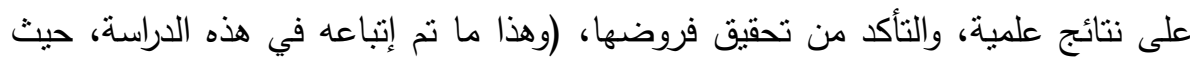
يتم ملاحظته عند متابعة الإطار المنهجي).

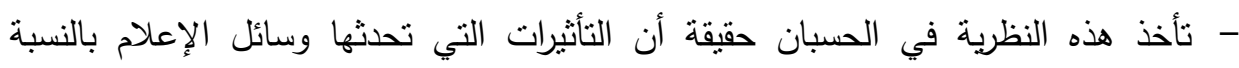
للجمهور ربما تؤدي إلى تأثيرات على النظام الاجتماعي وعلى النظام الإعلامي نفسه فتؤدي

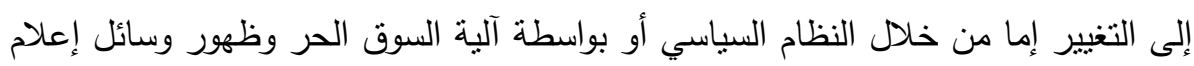
بديلة، (وذلك ما تم تطبيقه في منهج هذه الدراسة وأدوات جمع البيانات، المتمنتة في أداة الاستبيان ). - أهية الفيس بوك الخاصة لنظرية الاعتماد على وسائل الإعلام، (وهو وسيلة الاتصال التي

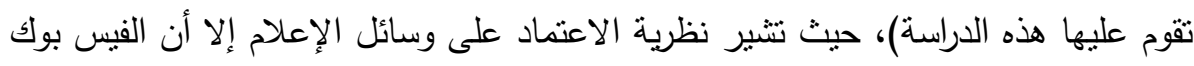

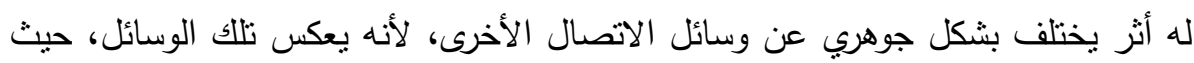


يستخدمه الثباب بشكل انتقائي وبجرعات مكثفة، ولهذا فإنه لديه القدرة على أن يستخدمه

$$
\text { الجمهور في الوقت المناس ب لهم. لكن. }
$$

\section{الاطار المنهمبيه اللقراسلة}

تتنمي هذه الدراسة الي البحوث الوصفية التي تستهدف الكثف عن الدور الذي تقوم به

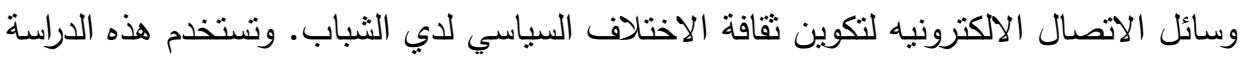
منهج المسح بالعينة باعتباره جها علميا منظما يساعد فى الحصول علي المعلومات والبيانات. أدوات جمع البيانات: جمعت البيانات عن طريث استمارة استنيان حيث قام الباحث باعداد

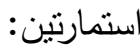
الأولي: لجمع البيانات المطلوبه والمعروضة علي المبحوثين بشأن تأثثر الفيس بوك علي ثقافة

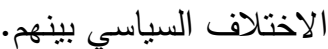
الثانية: استمارة بيانات شخصية لتحديد البعد البيئي والاجتماعي للمبحوثين. خطوات تصميم استمارة الاستبيان: قام الباحثون بإعداد استمارة استبيان لجمع المعلومات

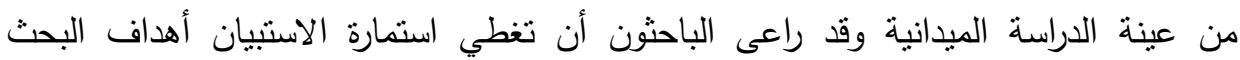
وتساؤلات الدراسة الميدانية، فشملت الاستمارة علي خمسة وعشرين سؤالا مقسمين الي الدحور الرئيسية للاراسة، ولقد تضمن إعداد استمارة الاستبيان عدة خطوات إجرائية شملت ما يلي: قام الباحثون بتحديد خمسة محاور للاستماره هي: المحور الأول: الثباب والسياسدة: ويتكون هذا المحور من ثناثة اسئله رئيسيه تقيس مدي وجود اهتمامات سياسية لدي المبحوثين، والوسيلة المستخدمة القضايا السياسية واستخدام المواقع

$$
\text { الحزبيه الالكترونيه ، الهمبه }
$$
المحور الثاني: مدي تعرض طلاب الجامعه لوسائل الاتصال الاككترونيه: ويتكون هذا المحور

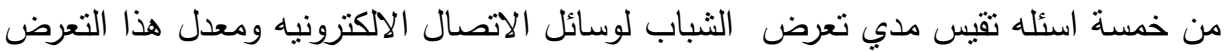

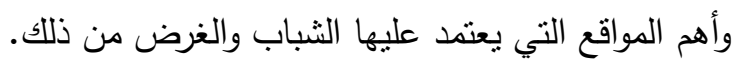


المحور الثالث: اقبال الثباب علي النقاش السياسي عبر الفيس بوك: ويتكون هذا المحور من خمسة أسئله تقيس مدي اقبال الثباب علي النقاش السياسي علي الفيس بوك وطبيعة ونوع القضايا محل النقاش وأسباب اجراء النقاش السياسي وأهم المعلومات التي يسعي الثباب للحصول عليها

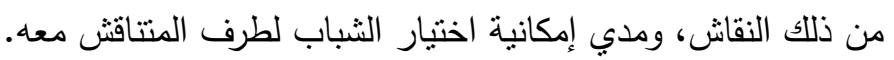
المحور الرابع: دور وسائل الاتصال الالكترونيه في اكساب طلاب الجامعة المعلومات السياسيه: ويتكون هذا المحور من سؤالين رئيسيين يقيسان رأي الثباب في دور وسائل الاتصال الاككترونيه في امداده بالمعلومات السياسيه المفيده، والاهداف السياسية التي يسعي لئي الثباب الحصول عليها من استخدام وسائل الاتصال. المحور الخامس: الاختلاف السياسي لاي الثباب: ويقيس هذا المحور المكون من عشرة أسئلة مدي توقع الثباب حدوث خلاف سياسي مع الطرف الاخر ومدي حرصه علي عدم حدوث الخلاف، وماالذي يفعله اذا حدث خلاف، ونوع أدوات الاقناع التي يستخدمها، وماذا كان يري التربي ان الاختلاف السياسي في مصلحة الوطن وهل نراعي الكوادر السياسية المصرية أداب

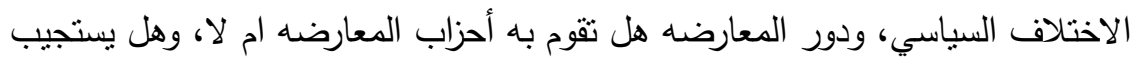

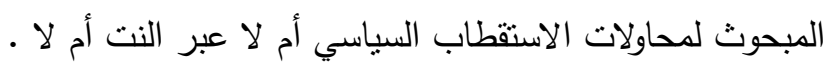
- قام الباحثون بتحديد أهداف الاستبيان من خلال مشكلة الدراسة وفروضها وتساؤلاتها

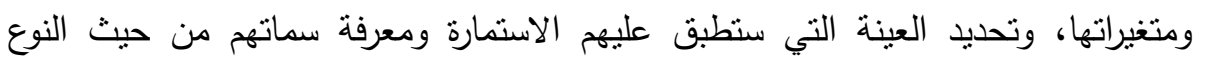
والسن ونوع الجامعة وذللك حتى يمكن الوقوف على صيغة مناسبة للمبحوثين من ناحية ولهدف الدراسة من ناحية أخرى. - تم صياغة الأسئلة بشكل علمى مبسط حتى يسهل على المبحوثين الإجابة عليها ويسهل على الباحثين جمع البيانات وتفريغها وتحليلها بشكل علمي دقيق. 


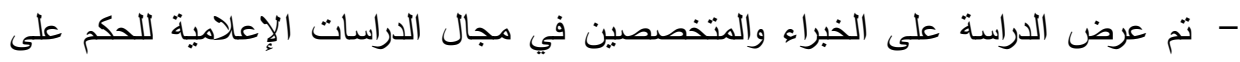
مدى صلاحيتها للنطبيق وبناء على ملاحظات السادة المحكمين تم تعديل الاستمارة في شكلها النهائي.

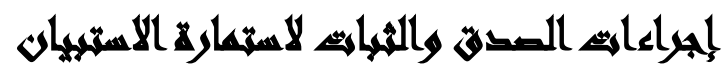

لكي يطمئن الباحث إلي عدم تسرب الخطأ في أي مرحلة من مراحل الدراسة، أخذ في

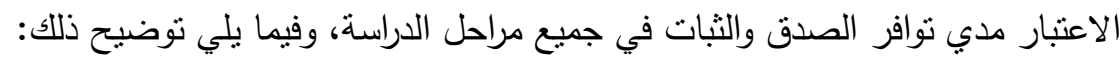
اختبار الصدق لاستمارة الاستبيان: هناك وسائل عدة لقياس صدق الاستبيان، وقد استخدم الباحث الصدق الظاهري الذي يقوم على أساس الفحص المبدأي لفقرات الاستبيان ومدى الإن الاتساق الداخلي لها، وهذا ما تم عمله من خلال عرض الاستمارة المقترحة على السادة لهادي

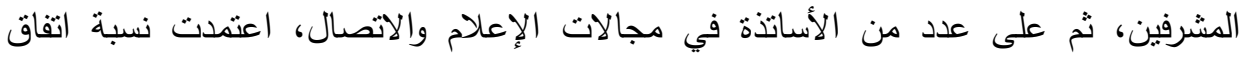

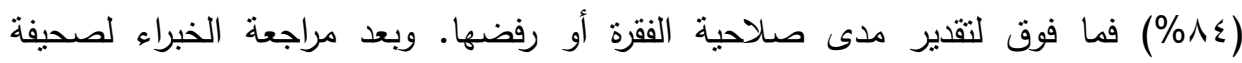

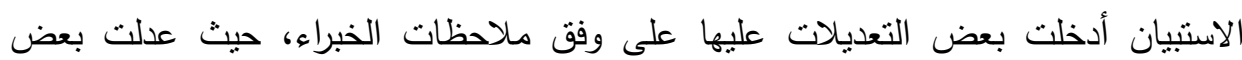
الأسئلة غير الواضحة وفي ضوء هذه الملاحظات خرج الباحث بالاستمارة النهائية وأصبحت جاهزة لتطبيق الإجراءات الميدانية.

اختبار الثبات لاستمارة الاستبيان: يشترط في أي أداة بحثية يستخدها الباحثون لجمع المعلومات أن يكون فيها قدر من الثبات، فالثبات هو الذي يجعل المعلومات التي تجمع جديرة

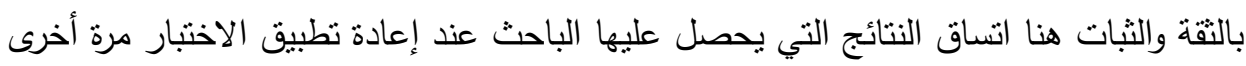
على الأفراد أنفسهم، وفي ظل الظروف نفسها. لذلك فقد اعتمد الباحث في إيجاد الثبات لأداة بحثها على طريقة إعادة الاختبار (TEST-RETEST)، وقد نم ذلك من خلال اختبار عينة

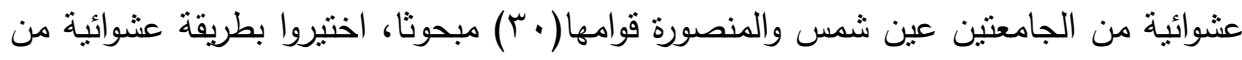
مجتمع الدراسة، وكانت الددة بين الاختبار الأول والثاني أسبوعين، وقد أظهرت النتائج أن درجة 
الاتفاق بالنسبة لجميع الأسئلة التي قيس ثباتها تتراوح بين درجة AV, • كحد أدنى ودرجة بو, • كد أعلى، وهي درجة ثبات مرتفعة جدًا.

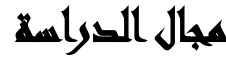

بشري: فئة الثباب الجامعي، ووقع اختيار الباحث علي طلاب قسمي الاجتماع والإعلام من

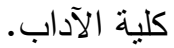

جغرافي: طلاب قسمي الاجتماع والإعلام بكلية الآداب، بجامعة المنصورة، باعتبارها جامعة

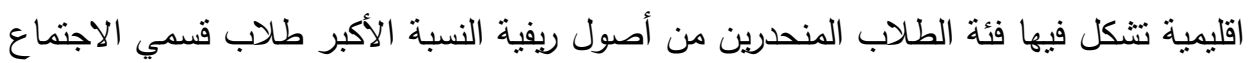
والإعلام بكلية الآداب، جامعة عين شمس، حيث تشكل فئة الطلاب الناشئين فى المجتمع

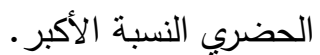

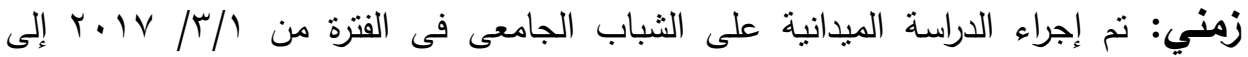

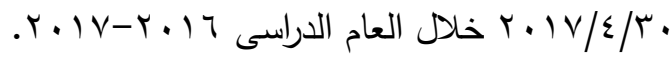

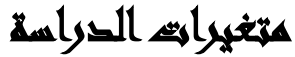

المستقل: وسائل الاتصال الاككترونيه ممنلة فى الفيس بوك. التابع: هو الاختلاف السياسي عند الثباب.

المتغيرات الوسيطة: ( النوع (ذكر وأنثي) - البعد البيئى (ريف وحضر) - المستوى

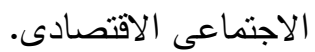

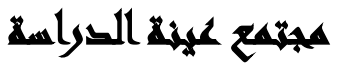

بري الباحث أن المجتمع الأفضل لدراسة ظاهرة البحث هو مجتمع شباب الجامعة باعتباره الاكثر تعرضا للفيس بوك كوسيلة اتصال الكترونيه متلي لاجراء الدرششة والحوار وتبادل الآراء وأيضا للحشد والتأييد فى الثورات والاعمال الاحتجاجية، إضافة الي أن الجامعة هي المجتمع لونس 180 
الأمتل لتكوين المفاهيم السياسية لدي الثباب وأنها واحدة من أهم منتجات القادة والزعماء السياسيين، وقد روعي في اختيار العينة المتغيرات الاجتماعية والتقافية لدي الثباب محل العينه

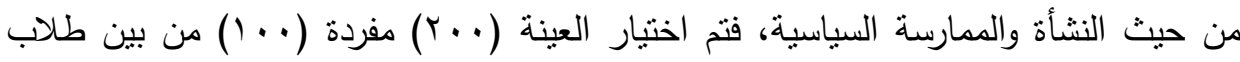
جامعة عين شمس باعتبارها جامعة حضرية و( · ل (1) من طلاب جامعة المنصورة باعتبارها جامعة إقليمية.

\section{النمأيج التراسة}

جدول رقم(1): توزيع المبحوثين عينة الدراسة وفقا لمتغير النوع بثأن مدى استخدامهم لوسائل

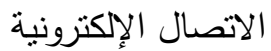

\begin{tabular}{|c|c|c|c|c|c|c|}
\hline \multirow{2}{*}{\multicolumn{2}{|c|}{ الإجمالى }} & \multicolumn{4}{|c|}{ متغير النوع } & \multirow{3}{*}{ مدى الاستخدام } \\
\hline & & \multicolumn{2}{|c|}{ إناث } & \multicolumn{2}{|c|}{ ذكور } & \\
\hline$\%$ & ك & $\%$ & ك & $\%$ & ك & \\
\hline NI & $17 Y$ & A. & A. & AT & AT & نعم \\
\hline 19 & $r \Lambda$ & $r$. & $r$. & 11 & 11 & آحبانا \\
\hline . & . & - & - & - & . & $y$ \\
\hline$\ldots$ & $r_{\ldots}$ & $\ldots$ & $\ldots$ & $\ldots$ & $1 \ldots$ & الإجمالى \\
\hline
\end{tabular}

- المحور الأول: مدى تعرض طلاب الجامعة لوسائل الاتصال الإكترونية:

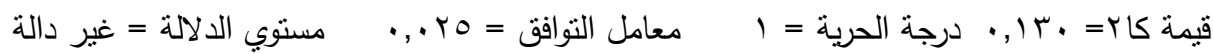
تظهر بيانات الجدول السابق توزيع استجابات المبحوثين وفقا لمتغير النوع (ذكور - إناث)

$$
\text { بشأن استخدامهم الاتصال الإكترونية وجاءت النتائج كالتالى: }
$$

- جاء في الترتيب الأول "تعم" بنسبة 1/\% من إجمالي عينة الدراسة مقسمة بين الذكور بنسبة

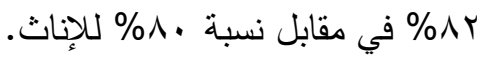

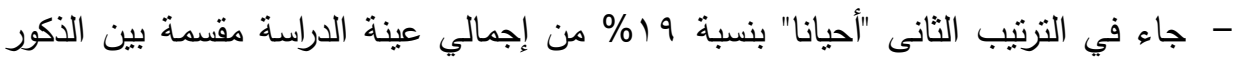

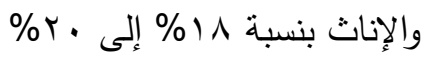

- وأخيرا في الترتيب الثالث "لا" بنسبة \% لكلا من الذكور والإناث من إجمالي عينة الدراسة.

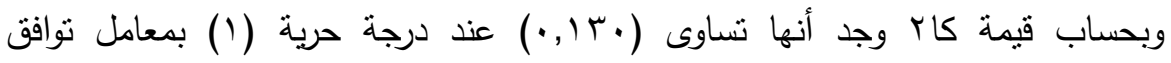

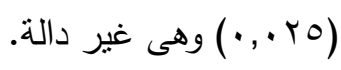


مما سبق نستتج أن: المبحوثين يستخدمون وسائل الاتصال الاككترونية بكثافة بنسبة 1) لما لها من استخدامات متعددة تفى باحتياجاتهم منل الحصول على معارف جديدة، وتكوين

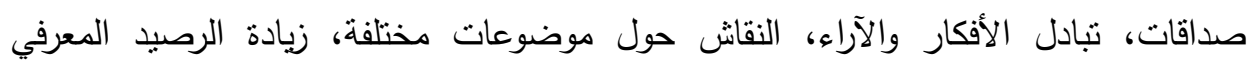

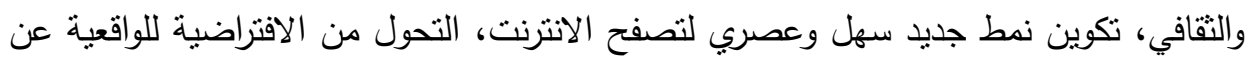
طريق تكوين صداقات عبر الانترنت ثم نطور العلاقة إلى أن تصبح صداقة حقيقية، المشاركة في ملتقيات وندوات، الإحاطة بجميع أخبار العالم الخارجي، المساهمة في التواصل السريع، والتعرف على الثخصيات المهمة، نافذة جديدة للتعبير عن الأفكار خاصة المدونات، سهولة التهارية

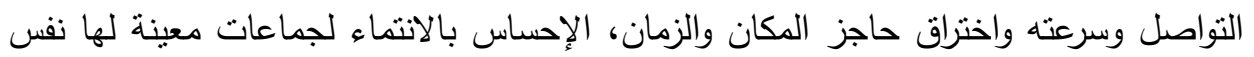

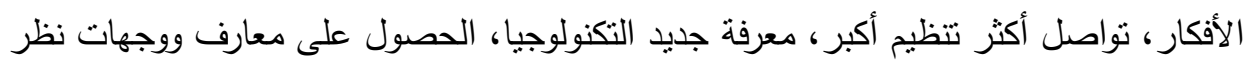

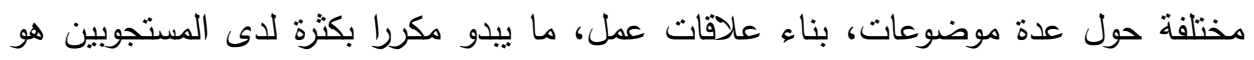

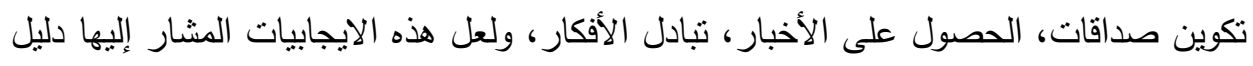

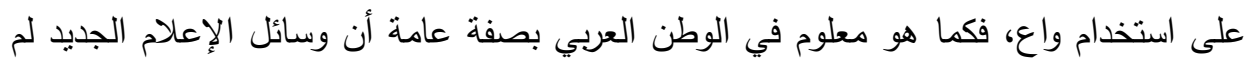

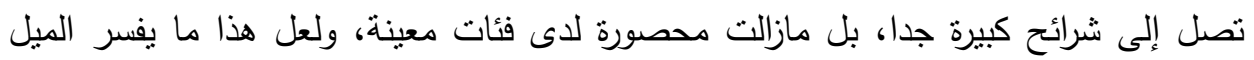
الواضح لاستخدام الشبكات الاجتماعية بفعالية، إضافة إلى ذلك أن الاستبيان لم يأخذ بعين الاعنبار الحصول على عينة ممثلة المحور الثانى: الثباب والسياسة: جدول رقم(ץ): توزيع المبحوثين عينة الدراسة وفقا لمتغير النوع بثأن مدى وجود اهتمامات

\begin{tabular}{|c|c|c|c|c|c|c|}
\hline & & & & \multicolumn{3}{|c|}{ سياسية لديهر } \\
\hline \multirow{2}{*}{\multicolumn{2}{|c|}{ الإجمالى }} & \multicolumn{4}{|c|}{ متغير النوع } & \multirow{3}{*}{ مدى الاهتمام السياسى } \\
\hline & & \multicolumn{2}{|c|}{ إناث } & \multicolumn{2}{|c|}{ ذكور } & \\
\hline$\%$ & ك5 & $\%$ & ك5 & $\%$ & S & \\
\hline 17,0 & $I V T$ & 10 & 10 & $\Lambda \Lambda$ & $\wedge \Lambda$ & أحيانا \\
\hline $1 \pi, 0$ & rV & 10 & 10 & Ir & Ir & دائما \\
\hline - & - & - & - & - & - & $y$ \\
\hline $1 \ldots$ & & $1 \ldots$ & $1 \ldots$ & $1 \ldots$ & $1 \ldots$ & الإجمالى \\
\hline
\end{tabular}


قيمة كاr=

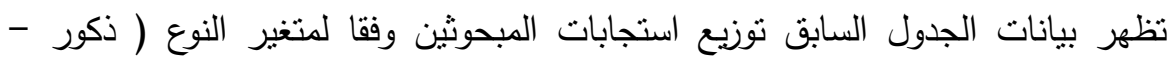

إنات) بشأن وجود اهتمامات سياسية لديهم وكاتت النتائج كالتالى:

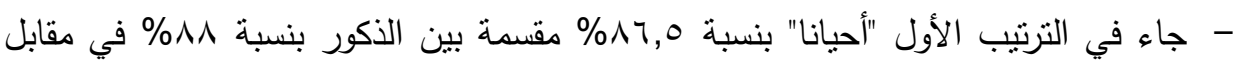

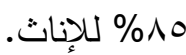

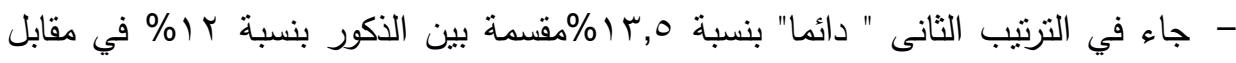
10 10 للإناث

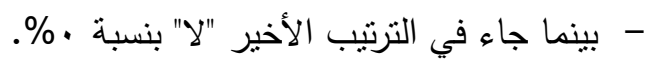

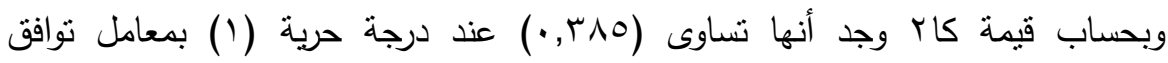

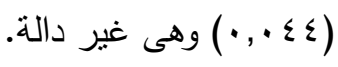

المحور الثالث: إقبال الثباب على النقاش السياسى عبر الفيس بوك:--

جدول رقم(ץ): توزيع المبحوثين عينة الدراسة وفقا لمتغير النوع بشأن مدى مدى قيامهم بمناقثة

\begin{tabular}{|c|c|c|c|c|c|c|}
\hline \multirow{2}{*}{\multicolumn{2}{|c|}{ الإجمالى }} & \multicolumn{4}{|c|}{ متغير النوع } & \multirow{3}{*}{ مدى المناقشثة } \\
\hline & & \multicolumn{2}{|c|}{ إناث } & \multicolumn{2}{|c|}{ ذكور } & \\
\hline$\%$ & ك & $\%$ & 5 & $\%$ & 5 & \\
\hline Vq & 101 & Ar & $\Lambda r$ & Vq & V & أحيانا \\
\hline IT & $r \varepsilon$ & 1. & 1. & $1 \varepsilon$ & $1 \varepsilon$ & دائما \\
\hline 9 & 11 & $\Lambda$ & $\Lambda$ & 1. & 1. & $y$ \\
\hline $1 \ldots$ & r.. & $1 \ldots$ & $1 \ldots$ & $1 \ldots$ & $1 \ldots$ & الإجمالى \\
\hline
\end{tabular}

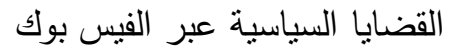

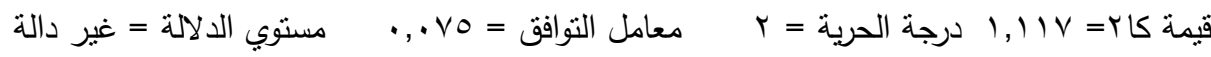
تظهر بيانات الجدول السابق توزيع استجابات المبحوثين وفقا لمتغير النوع (ذكور - إناث) بشأن مدى قيامهم بمناقتة القضايا السياسية عبر الفيس بوك وكاتت نتائجها كالتالى:

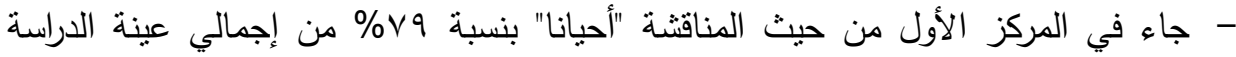

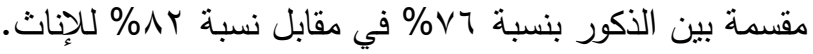


- يليه في المركز الثانى من حيث المناقثة " دائما" بنسبة r إ\% من إجمالي عينة الدراسة

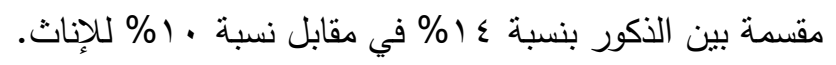

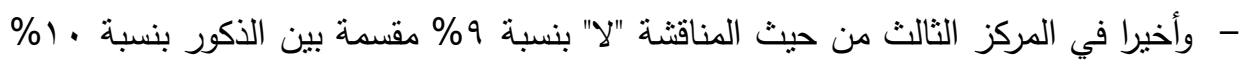
في مقابل نسبة ^^\% للإناث.

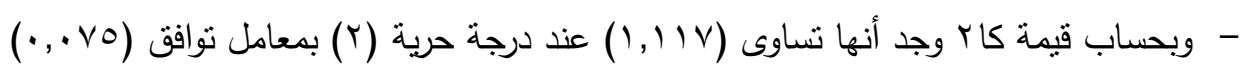
وهى غير دالة. مدى حرص المبحوثين على عدم حدوث خلاف السياسى بيذهم وبين الطرف الأخر.

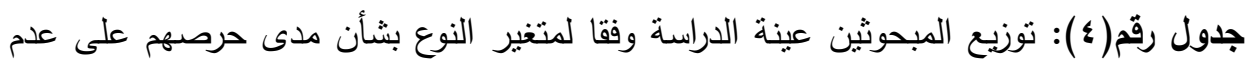
حدوث خلاف سياسى بينهم وبين الطرف الأخر

\begin{tabular}{|c|c|c|c|c|c|c|}
\hline \multirow{2}{*}{\multicolumn{2}{|c|}{ الإجمالى }} & \multicolumn{4}{|c|}{ متغير النوع } & \multirow{3}{*}{ مدى الحرع } \\
\hline & & \multicolumn{2}{|c|}{ إناث } & \multicolumn{2}{|c|}{ ذكور } & \\
\hline$\%$ & ك & $\%$ & ك & $\%$ & 5 & \\
\hline$\varepsilon \cdot, 0$ & NI & rᄉ & rᄉ & $\varepsilon r$ & $\varepsilon$ & دائماً \\
\hline$\varepsilon \cdot, 0$ & (1) & $\varepsilon \wedge$ & $\varepsilon \wedge$ & سץ & سץ & أحيانا \\
\hline 19 & ऍᄉ & $1 \varepsilon$ & $1 \varepsilon$ & $r \varepsilon$ & $r \varepsilon$ & $y$ \\
\hline $1 \ldots$ & $r .$. & $1 \cdots$ & $1 \cdots$ & $1 \cdots$ & $1 \cdots$ & الإجمالى \\
\hline
\end{tabular}

قيمة كاr= تظهر بيانات الجدول السابق توزيع استجابات المبحوثين وفقا لمتغير النوع (ذكور - إناث) بشأن مدى حرصهم على عدم حدوث خلاف سياسى بينهم وبين الطرف الآخر وكانت نتائجها كالتالى : بنان: - احتل المرتبة الأولى "دائما" بنسبة ه, •ـء\% من إجمالي عينة الدراسة مقسمة بين الذكور بنسبة rع\% في مقابل نسبة ^r\% للإناث.

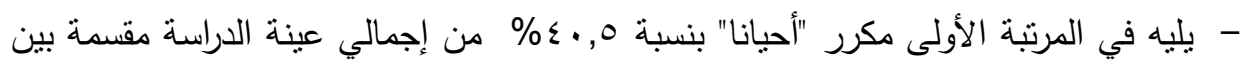

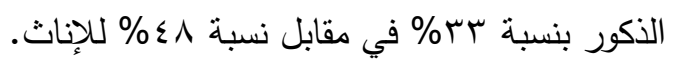


- بينما جاء في المرتبة الثانية "لا" بنسبة 9 1\% من إجمالي عينة الدراسة مقسمة بين الذكور

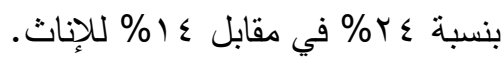

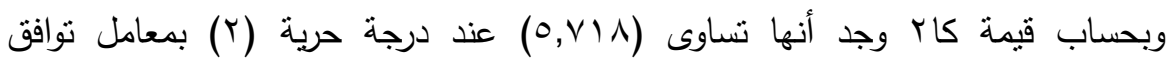

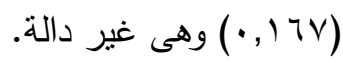

مما سبق نستنتج أن: أفراد العينة حريصون بنسبة ایه\% ( دائما - أحيانا)على عدم حدوث

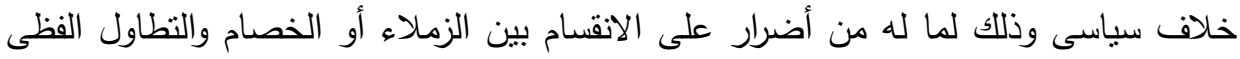

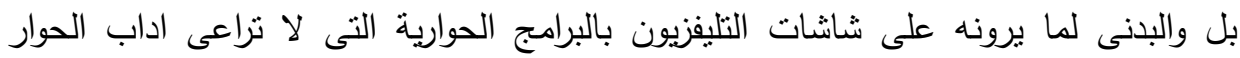

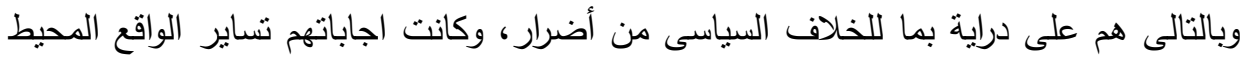
بهم فى الثارع وفى وسائل الإعلام.

ما يفعله المبحوثون إذا حلث خلاف السياسى بينهم ويبن الطرف الأخرم .

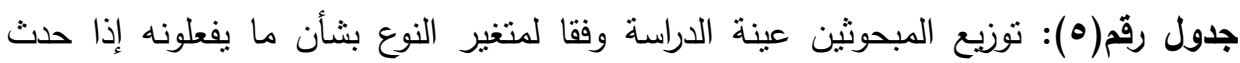
خلاف السياسى بينهم وبين الطرف الأخر

\begin{tabular}{|c|c|c|c|c|c|c|}
\hline \multirow{2}{*}{\multicolumn{2}{|c|}{ الإجمالى }} & \multicolumn{4}{|c|}{ متغير النوع } & \multirow{3}{*}{ ما يفعله المبحوث } \\
\hline & & \multicolumn{2}{|c|}{ إناث } & \multicolumn{2}{|c|}{ ذكور } & \\
\hline$\%$ & ك & $\%$ & ك & $\%$ & ك & \\
\hline $0 \leqslant, 0$ & 1.9 & 00 & 00 & $0 \leqslant$ & $0 \leqslant$ & أنقهج وجهة نظره \\
\hline$r \wedge, 0$ & OV & rA & rA & rq & rq & لا أناقتشه مرة أخرى \\
\hline iv & Tะ & iv & IV & IV & iv & أحاول اقناعه \\
\hline $1 \ldots$ & $r \ldots$ & $1 \ldots$ & $1 \ldots$ & $1 \ldots$ & $1 \ldots$ & الإجمالى \\
\hline
\end{tabular}

قيمة كاYY

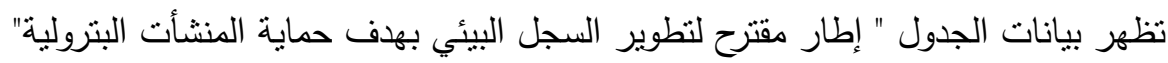

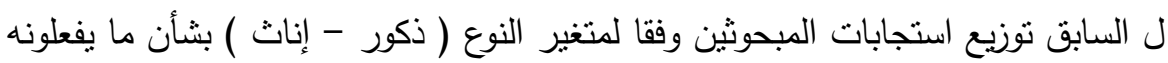
إذا حدث خلاف سياسى بينهم وبين الطرف الآخر وجاءت كالتالى:

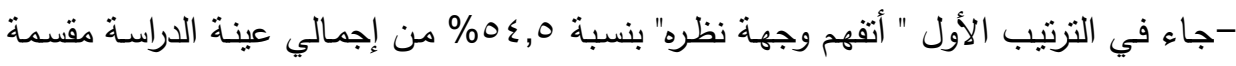
بنسبة ؛0\% للأكور في مقابل نسبة 00\% للإناث. 


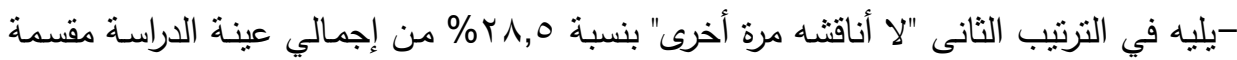

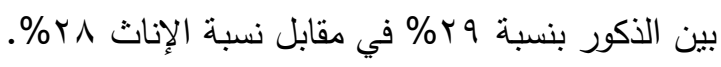

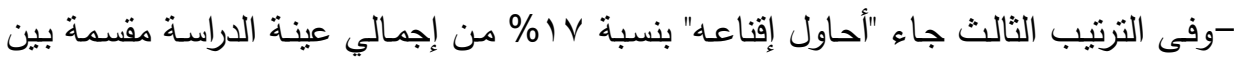

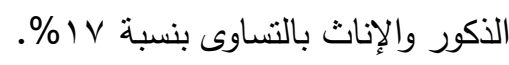

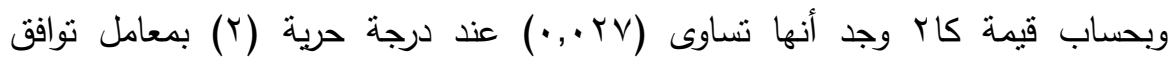

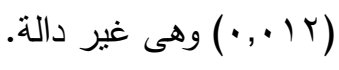

مما سبق نستنتج أن: عينة الدراسة جزء من المجتمع المصرى الذى ينسم بالتسامح ولذلك فهر يتفهمون وجهة النظر الأخرى بنسبة 0,ـ0\% حيث إن المجتمع المصرى مدرسة فى النسامح وتقبل الآخر على مدى تاريخه، ولكن هذا التسامح لم يجد فى الآونة الأخيرة من برعاه، وتفاعلت الته

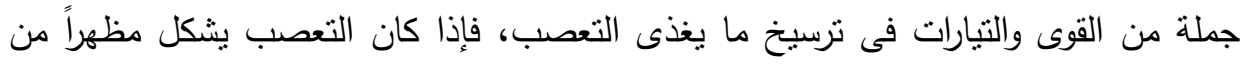

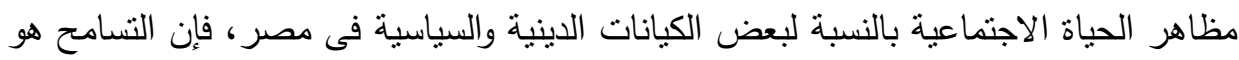

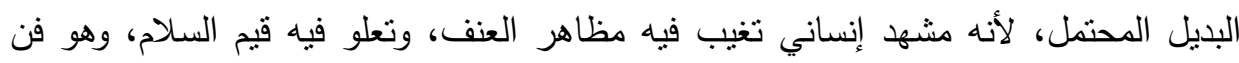

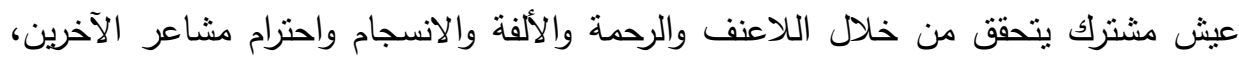
والسماحة وتجنب سوء الظن.

كما أن عينة الدراسة التى ترى التفاهم مع الآخر عند حدوث خلاف سياسى على وعى

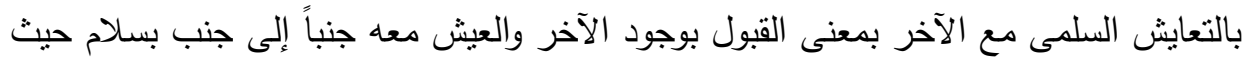

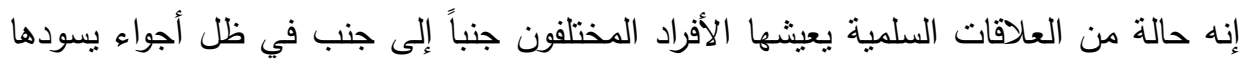

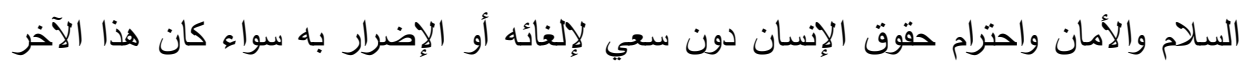

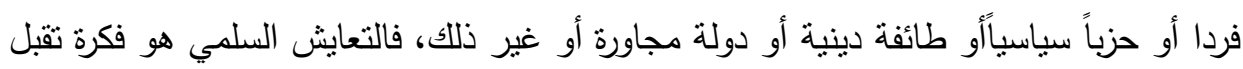

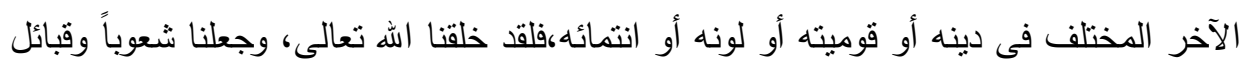
لنتعارف ونتعايش وفق قيم تحترم الإنسان، وبموجب ضوابط تكفل لكل فرد حقه في العيش بسلام

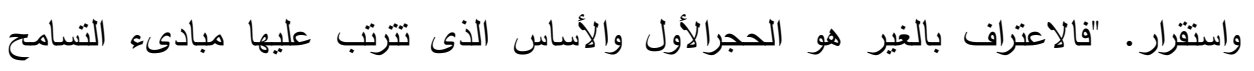

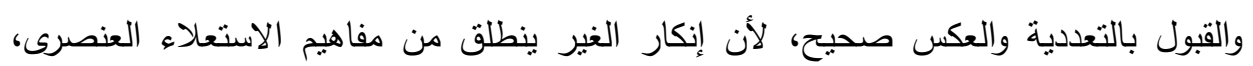


والرغبة الجامحة فى الهيمنة المطلقة التى تتكر فى الأصل وجود الطرف الآخر، وبنفس

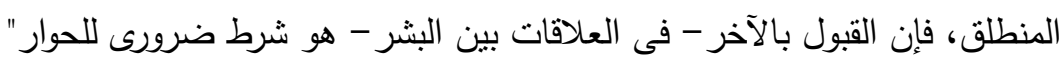

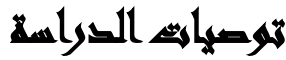

-ضرورة اهتمام القيادات السياسية والحزبية والأهلية بضرورة الاتصال المباشر مـع المواطنين من خلال وسائل الاتصال الالكترونيه لعرض وشرح المواقف السياسية التي يضطلعون بها فى مؤسساتهم وعرضها بسهولة ويسر للمتلقي والوقوف علي رأيه فى تلك المواقف والقضايا ومشاركته فى اتخاذ القرار بشأنها.

-الاهتمام بتربية الاجيال الجديده تربية سياسية صحيحة منذ بداية مراحل التعليم حتي نهايته وذللك من خلال ادخال مناهج دراسية جديدة تتيح التعلم والتتقيف السياسي واتاحة الفرصة للارسين بـاجراء تجـارب سياسية فى مدارسهم وجامعـاتهم تحـاكي مايحدث علـي السـاحة السياسية وتقييم تلك التجارب من المسؤولين فى الدولة والتعقيب عليها. -تدريب الثباب علي ممارسـة السياسـة فـى اطـار تتظيمي رسميا كان من خـلال المؤسسـات الرسمية فى الدولة كل فى تخصصه وأيضا من خلال المراكز البحثية التي تقوم علي امداد

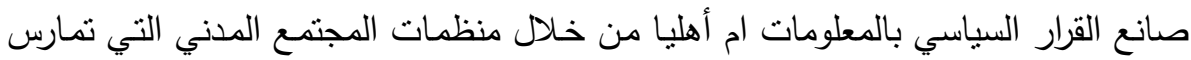
العمل السياسي بشكل قانوني حتي يتعلم الثناب علي أرض الواقع كيف يؤدي المواطن حق هق الدولة وكيف بطالبهخا بحقه عليها. -الارتقاء بمستوي الخطـاب والنقاش السياسـي فـى المحافل الرسـمية والثـعبية وارسـاء قواعد

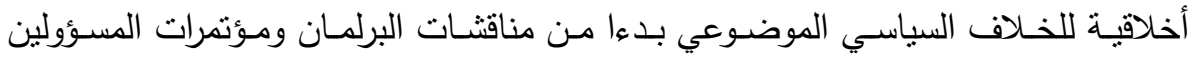
وانتهاء بالمؤتمرات الشعبية ووسائل الاعلام المختلفة. 


\section{المرالم}

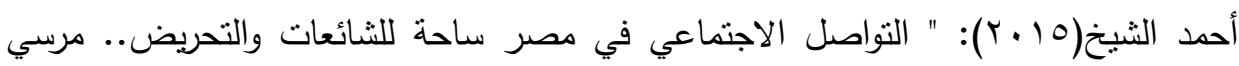

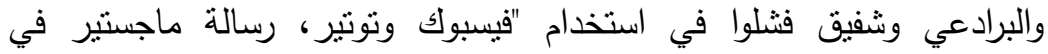
الإعلام التتموي من جامعة ويستمنسنز البريطانية

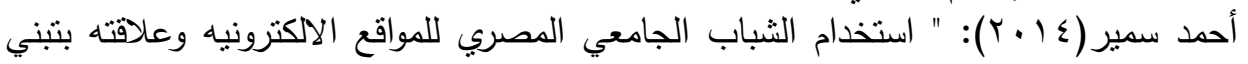

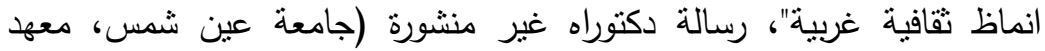
الدراسات العليا للطفولة.

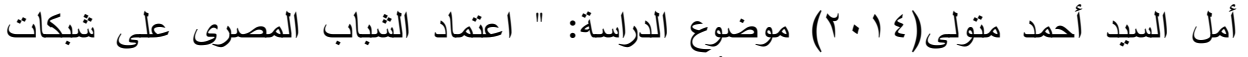

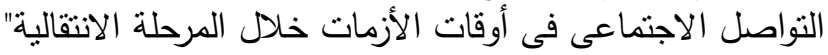

اندرو فيالا، ورقة بحثنة تقدم لمحة مفاهيمية وتاريخية عن مفهوم التسامح، نشر بموقع الأنع tavaana.orghttps://tolerance.tavaana.org/ar/content/\%D8\%A

7\%D9\%84\%D8\%AA\%D8\%B3\%D

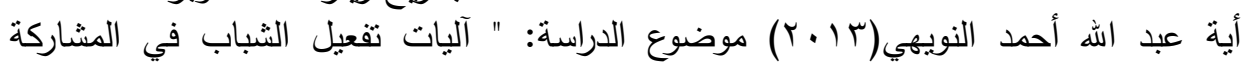
السياسية

حسن عماد مكاوي، ليلي حسين السيد (991 ام): الاتصال ونظرياته المعاصرة ، طا، (القاهرة

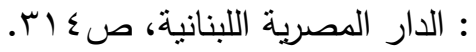

سامية محمد محمود ابو النصر ( 10 • ب): "استخدام طلاب الجامعات لمواقع الاحزاب السياسية

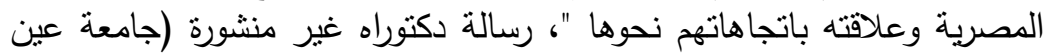

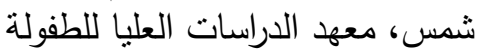

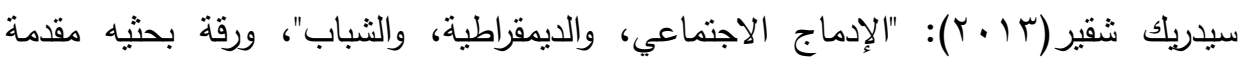

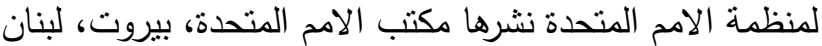

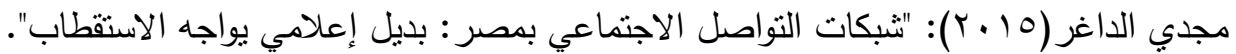

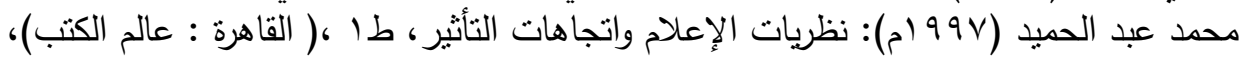

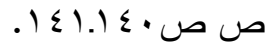

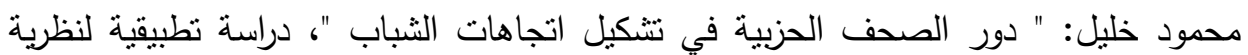

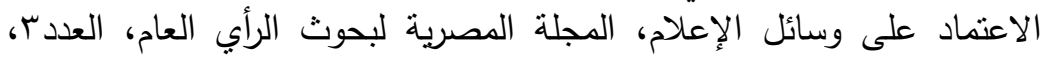

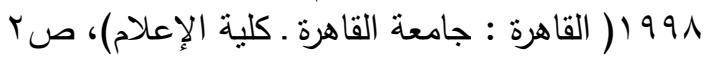

Denis Mc quail svin windhal : " Communication Models: for the Study Of communication ، 2ed New york ( longman ، 1995)p115 .

http://www.minshawi.com/vb/t1343.html . 29/3/2017 8:14pm. 
http://www.asskeenh.com/Gallery/text/ViewBooks.aspx?View=Tree\&No deID $=2 \&$ PageNo=1\&BookID $=28 \&$ page ID $=2$ $.29 / 3 / 2017.8: 27 \mathrm{pm}$.

http://www.alsahfe.com/index.php?id=2\%7C1319\&task=show.29/3/2017 $.8: 46 \mathrm{pm}$.

http://www.26sep.net/newsweekarticle.php?lng=arabic\&sid=26266. 29/3/2017.8:52pm.

http://www.26sep.net/newsweekarticle.php?lng=arabic\&sid=2626629/2/2017.8:55pm

http://www.startimes2.com/f.aspx?t=19387663.30/3/2017.7:15pm.

James waston : Media communication..An introduction to Theroy and process, (Macmillam press LTD , 1998), p.65.

John .C.p, lyhette . lee.s.\& Nicholas .p.l. Jr:" us and Japanese source reliance for enviromenal", Journalism quarterly, vol.65,no4, 1988, pp954_908.

John D.Owing:" Internationalizing media Theory :Trasition power.culture" , (London:Sage pwslication‘1996) pp.191192.

Kraus,S.and R. Perloff," Mass Media and political thought : An information - processing approach " , ( London: Bebrly Hills, Sage Publication ،1985), p.242.

Malvin L. Deflevr , Sandra J. Ball- Rokeach : " Theories Of mass communication", Op,cit, pp .248_249. 


\title{
EFFECT OF ELECTRONIC COMMUNICATION ON THE CULTURE OF POLITICAL DIFFERENCE AMONG YOUNG PEOPLE
}

\author{
Abd El Azim, S. S. ${ }^{(1)}$; Abdul Fattah, A. M. ${ }^{(2)}$ and Omar, A. H. \\ 1) Faculty of Arts, Ain Shams University.2) Faculty of Arts, Zagazig \\ University.
}

\begin{abstract}
In the face of unchecked and unprofessional information flows, many print, audio and video media have resorted to more sophisticated means of information technology in order to communicate their message to the recipient and thus maintain the credibility of the parent medium. Information is readily available on the mobile phone at any time to the user but lacks ) To the state of communication or comment and therefore lacks the element of difference of opinion for non-circulation. In this context, there have been numerous scientific studies that dealt with the adoption of the electronic media by the youth to form political concepts and expand their perceptions and work on knowledge of all the events that are taking place in the political arena. They relied on two things. First, it is to view Meincher via electronic means without checking or searching. From the sources that confirm the credibility of this information. The second is the political discussions that take place between them and their peers or among the intellectuals through these means. They are not indifferent to the conditions and rules of difference between the different groups in culture, education and political practice, and the neglect of the environmental and biological factors of the interlocutors. Hence, the aim of this study is to reveal the extent of Egyptian youth's interest in political debate through the electronic media and to reach the behaviors of Egyptian youth in the event of political


differences through the electronic media. This study is especially important in the need to fill the research gap represented by the impact of the electronic media - especially Facebook as the most widely used among young people according to the latest scientific statistics - on the culture of political difference among young people. This descriptive study used the field survey methodology on a sample of students The data collection tool was the first questionnaire: to collect the required data and presented to the respondents about the impact of Facebook on the culture of political difference between them. And the second: a personal data form to determine the environmental and social dimension of the respondents. The study reached several results, the most important of which are: The respondents are keen (81\%) (always - sometimes) on the absence of a political dispute because of its damage to the division among colleagues. The study concluded several recommendations, including: raising the level of discourse and political debate in official and popular forums and establishing ethical rules for substantive political differences. 